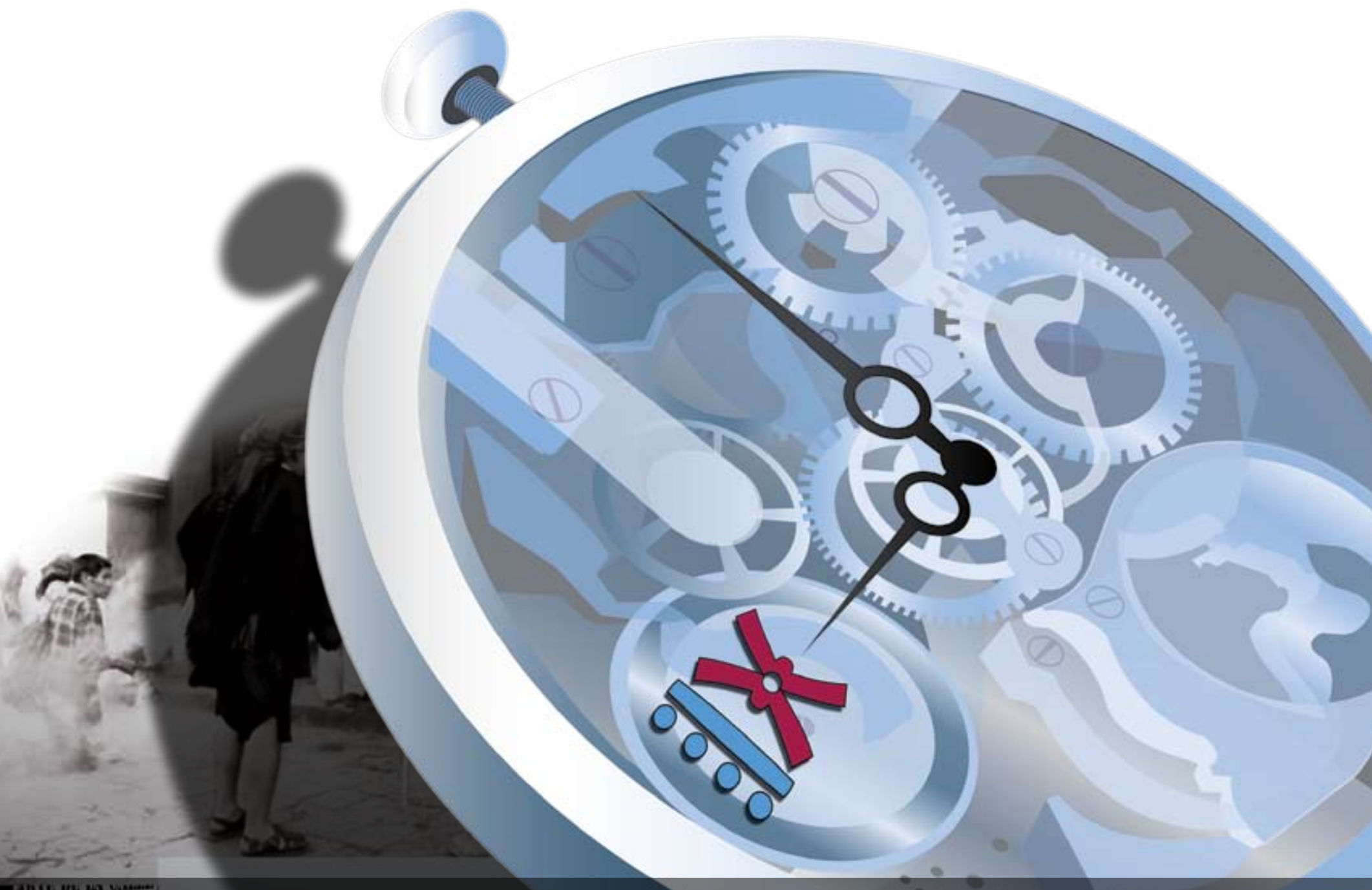

$9^{\circ}$ C O N G R E S O 2. CENTROAMERICANO DE H ISTO R I A

Universidad de Costa Rica

ISSN 1409-469X

Fecha de recepción: 15 de mayo 2008 Fecha de aceptación: 30 de mayo 2008

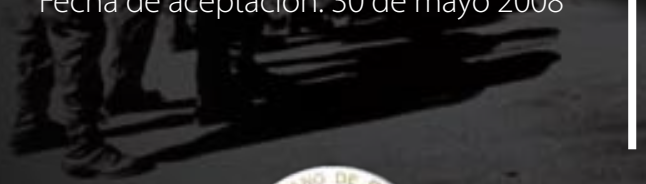

LA CAMPAÑA ELECTORAL DE 1970 Y EL PAPEL DEL PARTIDO VANGUARDIA POPULAR

Miembros del Consejo Editorial:

Dr. Ronny Viales, Dr. Juan José Marín

Editores Técnicos:

Allan Fonseca, Andrés Cruz, Gabriela Soto
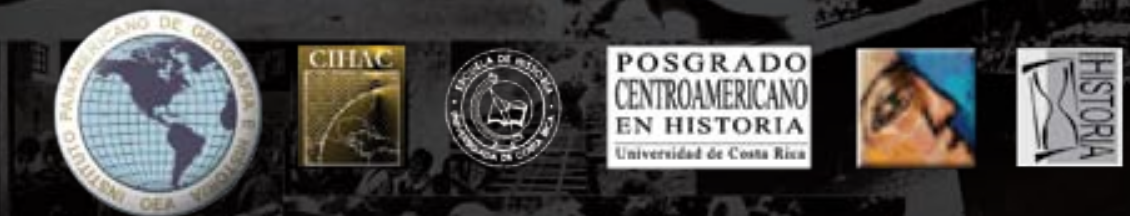
Indexaciones: Repositorio de Revistas UCR, DIALNET, Latindex, REDALYC Directorio y recolector de recursos digitales del Ministerio de Cultura de España, Directory of Open Access Journals. Diálogos Revista Electrónica de Historia ISSN 1409-469X. Número especial 2008. Dirección web: http://historia.fcs.ucr.ac.cr/dialogos.htm

\title{
LA CAMPAÑA ELECTORAL DE 1970 Y EL PAPEL DEL PARTIDO VANGUARDIA POPULAR
}

\author{
Gerardo Contreras (Contre) \\ Coordinador Sección Historia de la Cultura. Escuela \\ de Estudios Generales. Universidad de Costa Rica. \\ gcontre25@gmail.com
}




\section{INTRODUCCIÓN}

Es muy importante, desarrollar la tarea de escudriñar, auscultar, investigar con profundidad, la razón o razones que explican tal o cual hecho histórico, máxime si tomamos en consideración la premisa marxista de que no es la conciencia la que determina al ser, sino que es el ser social el que determina la conciencia, huelga advertir, que las personas no somos objetos, sino que somos sujetos sociales, que de una u otra manera contribuimos al quehacer en las más diversas manifestaciones de la sociedad (1).

Por otra parte, nos anima estudiar esta faceta de la historia política de Costa Rica, y particularmente del Partido Vanguardia Popular (Partido Comunista), desde la óptica de contribuir a elaborar Historia No Oficial, pero no historia tradicional, sino Historia No Oficial Emancipadora.

Trataremos en la medida de nuestras posibilidades, ejercer el principio elaborado por Antonio Gramsci, al señalar que se debe "Hacer la historia, de lo contemporáneo” (2).

Y dentro de esa práctica por construir el discurso histórico, en mi concepto es muy aleccionador lo que plantea el historiador costarricense, Víctor Hugo Acuña Ortega, cuando afirmó: "Posiblemente tendrán que aprender a moderar su fascinación por esas cosas viejas, con el fin de descubrir que su importancia no radica en que sean raras, exótica o hasta hermosas, sino, principalmente en que son rastros de la experiencia humana de otros tiempos” (3).

De modo que, es fundamental para escribir una faceta de la historia política patria NO oficial y emancipadora, caminar por las esencias, pero sobre la realidad, vale decir, tratar en la medida de lo posible, reconocer en el hecho histórico analizado, las fortalezas y las limitaciones. 


\section{PROMULGACIÓN DEL DECRETO-LEY \# 105 Y DEL ARTÍTULO 98 EN LA CONSTITUCIÓN POLÍTICA DE COSTA RICA}

Necesariamente, para poder tener una comprensión amplia del por qué, el Partido Vanguardia Popular, logra participar después de 1948, hasta el año 1970 en la Campaña Electoral para la elección de Presidente de la República, Diputados a la Asamblea Legislativa, Regidores a las Municipalidades, es preciso remontarse al mismo año 1948, primero para conocer la conducta de la Junta Fundadora de la Segunda República y posteriormente el accionar de la Asamblea Nacional Constituyente referente a la temática del partido político en mención.

Como es de todos conocido, el conflicto bélico denominado Guerra Civil de 1948, concluyó cuando en lo fundamental los dos jefes políticos de las fuerzas en contienda llegan a un acuerdo el día 18 de abril en horas de la noche, en el lugar denominado Ochomogo.

Ahí se suscitó un diálogo franco y abierto, entre Manuel Mora Valverde, Secretario General del Partido Vanguardia Popular y José Figueres Ferrer, Jefe del Ejército de Liberación Nacional, fueron testigos de excepción en ese diálogo el comunista Carlos Luis Fallas Sibaja (CALUFA) y el Presbítero Benjamín Núñez.

Se acordó, mantener la legislación social aprobada durante las administraciones de Calderón Guardia y Teodoro Picado; y respetar, la legalidad del Partido Vanguardia Popular y de la Confederación de Trabajadores de Costa Rica.

Fue sobre esas bases, que se firmó en la Embajada de México, el día 19 de abril de 1948 el acuerdo definitivo por poner fin a la Guerra Civil; la historia conoce estos dos hechos como el Pacto de Ochomogo y el Pacto de la Embajada de México.

Una vez instalada la Junta Fundadora de la Segunda República, presidida por don José Figueres Ferrer, se desató una represión contra el Partido Vanguardia Popular y contra el movimiento obrero y popular. 
No podemos dejar pasar inadvertido, que en ese momento histórico, el mundo entero vivía ya inmerso en el marco del fenómeno de las relaciones internacionales, denominado la Guerra Fría.

No obstante, que don José Figueres Ferrer, había adquirido el compromiso de respetar la legalidad del Partido Vanguardia Popular (Partido Comunista), hubo presiones muy fuertes, unas de carácter interno, esto es, sectores de la oligarquía costarricense, que tenían entre su proyecto eliminar a los comunistas, entre ellos destacan Frank Marshall, Viko Starke, y miembros de la colonia alemana acantonada en el país, que no le perdonaban a los comunistas ticos, haber sido partícipes del destierro de algunos de ellos a campos de concentración que los Aliados tenían en los Estados Unidos de América; y un factor externo muy evidente fue la administración estadounidense, la cual no estaba de acuerdo en la permanencia de los comunistas con cuotas de poder dentro del aparato del Estado.

Don José Figueres Ferrer, terminó aceptando las condiciones impuestas por estos dos sectores, y sin ningún sonrojo, su respuesta fue "El Partido Vanguardia Popular, el partido comunista de aquel tiempo se proscribió complaciendo a una fuerte corriente de opinión pública” (4).

De esta manera, el 17 de julio de 1948 se emitió el Decreto-Ley \# 105, de la Junta Fundadora de la Segunda República, el cual entre otros aspectos señala: "5. Que en América Latina existen en casi todas las repúblicas, partidos comunistas dirigidos o inspirados desde la metrópoli soviética, empeñados activamente en preparar el derrumbamiento de las instituciones republicanas ... 10.- Que dicho Partido Vanguardia Popular, durante los últimos seis años, a pesar de nombres adoptados para disimular su vinculación ideológica con los Soviets, han seguido fielmente la política del Kremlin y se ha revelado a través de sus actuaciones y publicaciones como un admirador de los dirigentes rusos y un obediente servidor de su política internacional ... Por tanto, DECRETA 3.- Los dirigentes y militantes de las organizaciones prohibidas en los artículos anteriores incurrirán por el hecho de serlo en la comisión de delito, que prevé y pena el artículo 354 del Código Penal ... 5.- Los indiciados por el delito definido en el artículo 3 anterior, no podrán ser excarcelados durante la tramitación del juicio ... 7.- Declárase comprendido expresamente en la prohibición del artículo primero al Partido Vanguardia Popular” (5). 
Por otra parte, una vez que inició sus labores la Asamblea Nacional Constituyente, en el mes de junio de 1949, el diputado Fernando Volio Sancho, presentó una moción con el propósito de establecer "Prohibiciones para aquellos partidos que, por sus procedimientos, programas y vinculaciones internacionales, atenten contra los principios democráticos o contra la soberanía nacional” (6).

Considero de suma importancia, transcribir los argumentos del Diputado Volio Sancho, para poder analizar el contenido político-ideológico de su discurso. El apuntó lo que sigue: “Con la sinceridad que procura una arraigada convicción, pienso que el sistema que hemos forjado para la institución del sufragio y la estructura misma de la nueva Carta, quedarían falseadas por su base si no estableciéramos en el texto constitucional disposiciones encaminadas a impedir que Partidos de tendencias antidemocráticas destruyan, lo que precisamente lo que con tanto afán estamos construyendo ... el Partido Demócrata declara que combatirá en todos sus reductos al comunismo costarricense, cualquiera que sea el nombre que adopte, pues además de considerarlo autor y cómplice de graves males nacionales, lo tiene por una avanzada de la política soviética de invasión y por la vanguardia del ejército comunista, evidente quintacolumna de las fuerzas del mal ... Costa Rica debe sumarse fervorosamente a la obra americana de preservación democrática, especialmente por su posición geográfica en el centro del Nuevo Mundo, a donde habrá de converger lo más crudo de la guerra en el caso no improbable, de un conflicto armado entre Oriente y Occidente ... Las razones que movieron a la Junta de Gobierno a declarar ilegales las actividades del partido comunista Vanguardia Popular, existen ahora - y seguramente con mayor fuerza - para que la Asamblea Nacional Constituyente dicte un precepto para salvaguardar la integridad de las instituciones que nos legaron nuestros abuelos, en armonía con los que han debido a adoptar los demás países amenazados por la penetración totalitaria ... Los Partidos Unión Nacional y Social Demócrata, que forman la mayoría de la representación popular encarnada en esta Asamblea han mantenido irreductible actitud anti-comunista en todas las diversas etapas de la lucha de liberación y esa voluntad la han afirmado en el terreno de los hechos y con el calor de una sincera convicción democrática, las veces que ha sido necesario y allí donde ha sido necesario” (7). 
Asimismo, hubo tres destacados diputados constituyentes que avalaron las tesis del diputado Volio Sancho, y que por su trayectoria en la vida académica de nuestro país, es conveniente que se conozcan sus criterios, ello para que podamos precisar, el nivel de anticomunismo que existía en la clase política dominante.

Don Luis Dobles Segreda expresó: “... que si el Partido Comunista fuera de extracción costarricense, si hubiese nacido aquí, si sustentara ideas nacionales, no tendría ningún inconveniente en que se le permitiera participar en nuestra vida política. Pero es sabido, que el partido comunista no es costarricense. Por el contrario sigue órdenes que vienen de Moscú. Sus doctrinas son exóticas, además, los comunistas no pueden considerarse como costarricenses, porque han jurado fidelidad a una potencia extraña. Por el solo hecho de su condición de comunistas han perdido su nacionalidad ... Quienes se han adherido al comunismo internacional, han hecho renuncia de su ciudadanía de costarricenses”; por otra parte añadió el diputado José Joaquín Jiménez Núñez: "Doctrinas entonces que en vez de unir, vienen a disociar, que al espíritu creador de la doctrina y la concordia oponen la violencia y la fuerza bruta ... no pueden tener cabida en el Estatuto Supremo de una Patria como la nuestra"; y reafirmó el diputado Luis Felipe González Flores: "Para defender la libertad y los principios de la democracia ha habido necesidad en determinados momentos de restringir la libertad misma ... Muy conocida ha sido la actitud del comunismo en los últimos tiempos y que constituye su acción política. El comunismo mientras está abajo pedirá libertad y cuando está arriba ejerce el despotismo” (8).

\section{VIOLACIONES A LOS DERECHOS DEMOCRÁTICOS}

En razón, de la legislación promulgada por la Junta Fundadora de la Segunda República y por disposición constitucional plasmada en el artículo 98, Párrafo Segundo, el nivel de represión al Partido Vanguardia Popular no se hizo esperar.

Ya para el mes de mayo de 1948, en la Penitenciaría Central, habían aproximadamente unos mil comunistas presos. Al respecto apuntó el Profesor Carlos Luis Sáenz: “A media noche, frente a mi casa, se detuvo un camión lleno de policías armados ... Salí, me apresaron, subí al camión, allí iban otros presos políticos. Nos apearon en la Penitenciaría ... Por primera vez 
conocimos la prisión, la cárcel; tres meses presos en la Penitenciaría, poblando alternativamente uno y otro de los llamados "patios" del penal ... Recordemos algunos de los nombres de los compañeros de prisión, Fabián Dobles, Manuel Picado, Jaime Cerdas, Luis Carballo, Carlos Luis Fallas, Arnoldo Ferreto, Guillermo Fernández, Adolfo Braña, Naranjo ... multitud de obreros y de campesinos, separados de sus hogares y de sus quehaceres ... Una alta moral caracterizó la conducta de todos los reclusos: sin altanerías, pero sin miedo; no nos dejamos humillar ni abatir nuestra bandera de combate” (9), La represión continuó, de manera que los comunistas tuvieron que pasar a la clandestinidad, sus periódicos fueron prohibidos, sus imprentas clausuradas, la emisora "Ecos del 56" desmantelada, y en diciembre de 1948 fueron asesinados a la altura del Codo del Diablo, los comunistas Federico Picado Sáenz, quien había sido electo diputado por la provincia de Limón en las elecciones de febrero de 1948, Octavio Sáenz, Tobías Vaglio y Lucio Ibarra, sobre este horrendo crimen el Partido Vanguardia Popular expresó que: "la responsabilidad de este abominable acto debía recaer en la persona de Gonzalo Facio Segreda. Facio es el responsable del crimen más negro que registra la historia nacional. Facio era el Ministro de Justicia en aquellos días en que el Gobernador de Limón y otras autoridades del puerto recibieron un telefonazo ordenando el brutal asesinato de los dirigentes comunistas y sindicales de la zona atlántica. ¿Quién dio ese telefonazo? ¿Por qué Facio nunca se ha atrevido a responder el cargo que se le ha hecho de que él fue el responsable directo del crimen?” (10).

Dentro de la dinámica del movimiento sindical, el nivel de persecusión se dio en la zona sur, cuando la United Fruit Co., despidió a todos aquellos obreros bananeros que se habían integrado a la Columna Liniera, los cuales habían defendido arduamente la promulgación de las garantías sociales (11).

Siempre en el orden de la persecusión, la Junta Fundadora de la Segunda República, emitió el Decreto-Ley \# 306 del 17 de diciembre de 1948, el cual reza: “... se consideran despedidos de los cargos, puestos, o funciones que desempeñen al servicio del Estado, de sus instituciones autónomas o semiautónomas todas aquellas personas de reconocida filiación calderonista o comunista”, este mismo Decreto dejaba sin efecto los artículos 29, 30 y 31 del Código de Trabajo para efectos del pago de prestaciones legales (12). 
Ya durante el gobierno de don Otilio Ulate Blanco, continuó el hostigamiento hacia la clase trabajadora, pues los señores diputados Carlos Fernández Prestinary y Fernando Volio Sancho, presentaron a la Asamblea Legislativa, un proyecto de Ley con el fin de reformar el Código de Trabajo para prohibir el funcionamiento de los sindicatos de ideas antidemocráticas (13).

A pesar de lo anterior, el Partido Vanguardia Popular, desde la clandestinidad, encargó a varios militantes reconstruir el movimiento sindical clasista, entre ellos a José Meléndez Ibarra, Gonzalo Sierra Cantillo, Alvaro Montero Vega, Juan Rafael Solís Barboza, Norberto Contreras, Isaías Marchena, Víctor Mora, Juan Rafael Morales, y otros militantes. El trabajo tesonero en el terreno sindical permitió aún en medio de condiciones hostiles, fundar en el mes de junio de 1953, la Confederación General de Trabajadores Costarricenses.

En el transcurso del año 1954, el diputado Gonzalo Facio Segreda, presentó otro proyecto de ley, con el propósito de prohibir que en las juntas directivas de los sindicatos fuesen nombradas personas que se consideraran simpatizantes y militantes del Partido Vanguardia Popular, el proyecto proponía de uno a cinco años de prisión para quienes violentaran esta norma, además de exigirle a los trabajadores dar fe bajo juramento de su credo político (14).

En el plano político-electoral, el partido Vanguardia Popular siempre se dispuso a inscribir un partido político, toda vez que se convocaba a elecciones generales, de esta forma el Tribunal Supremo de Elecciones proscribió en 1952 el Partido Progresista Independiente, quien postuló a Joaquín García Monge como su candidato a Diputado en la provincia de San José. En tales circunstancias, la Dirección del Partido Vanguardia Popular, llamó a votar por la candidatura de don Fernando Castro Cervantes, pues el fin era oponerse a don José Figueres, quien era el candidato del Partido Liberación Nacional.

De cara a las elecciones de 1958, los comunistas formularon el proyecto político denominado Partido Socialista, encabezado por el destacado escritor Fabián Dobles, de igual manera el Tribunal Supremo de Elecciones lo proscribió; en esta oportunidad la dirigencia vanguardista, convocó a depositar el voto por el candidato Lic. Mario Echandi Jiménez, quien 
resultó electo presidente. Durante este período de gobierno, el Partido continuó su trabajo de organización, y a pesar de la ilegalidad, se crearon en donde se pudo los locales denominados Centro Obrero de Estudios Sociales, los cuales en la práctica eran los locales del Partido Comunista, muchos de ellos funcionaban en las casas de habitación de militantes del partido.

Para la campaña electoral de 1962, los militantes del Partido Vanguardia Popular votaron en las papeletas del Partido Acción Democrática Popular, este fue un partido creado por don Enrique Obregón Valverde, y otros liberacionistas, que en ese momento se retiraron del Partido Liberación Nacional, pues creían que lo fundamental era dar todo su apoyo a la naciente Revolución Cubana, debe destacarse que en ninguna papeleta de ese partido figuró ningún militante de Vanguardia Popular.

Otra afrenta a la democracia costarricense, se puso de manifiesto en 1965, cuando el Tribunal Supremo de Elecciones, proscribió el proyecto vanguardista denominado Partido Acción Popular Socialista (P.A.P.S.), en esa oportunidad "Vanguardia Popular, acometió la tarea de entrar en negociaciones con el Partido Liberación Nacional ... la militancia y base social de apoyo, votaría por las tres papeletas de Liberación Nacional a cambio de que una vez en el gobierno, el Partido Liberación Nacional promovería la reforma constitucional para eliminar el susodicho párrafo segundo del artículo 98 de la Constitución Política. Esta decisión tomada por la Comisión Política del Partido Vanguardia Popular, no fue asimilada con beneplácito por las bases de la organización partidaria ... ¿ ¿votar por los que mandaron al exilio a los camaradas? ¿Darle el voto a quienes fueron partícipes de que la comunista Carmen Lyra no pudiese morir en su tierra natal? ¿Apoyar electoralmente a quienes asesinaron a los comunistas en el Codo del Diablo? ¿Sufragar a favor de los que redactaron el Decreto-Ley \# 105 y el párrafo segundo del artículo 98, proscribiendo al Partido Comunista Popular y a la Confederación de Trabajadores de Costa Rica? ... Se acató la disposición pero no con el mejor ánimo” (15).

No hay duda que la anterior contradicción provocó niveles de incertidumbre en la militancia del Partido Vanguardia Popular, pero debe tenerse siempre una concepción política clara, la cual permita estudiar la realidad del momento, o sea, análisis concreto de situaciones concretas, sin menospreciar en absoluto la experiencia histórica del carácter de la lucha de clases 
que hubo en un pasado, si se quiere reciente, bien nos lo enseña Rosa Luxemburgo, al plantear: “... la lucha práctica cotidiana, que tiende a alcanzar una reforma social, a mejorar, aún dentro de lo existente, la situación del pueblo trabajador, a conseguir instituciones democráticas, constituye más bien el único camino por donde el proletariado ha de llevar su lucha de clase por donde ha de arribar a su último objetivo, a la conquista del poder político ... la reforma social y la revolución social forman un todo inseparable, por cuanto el camino ha de ser la lucha por la reforma y la revolución social, el fin" (16).

Lo que si deja como enseñanza histórica, el trabajo permanente, riguroso, disciplinado de la militancia adscrita al Partido Vanguardia Popular, es que todo ello fue expresión de la lucha de clases, la que se dio de modo ininterrumpido en los planos político, ideológico , económico, desde el momento mismo de la proscripción del Partido Comunista de la vida política nacional, esto no quiere decir ni por asomo, que toda acción fuera libre de errores, por supuesto que errores hubo, no obstante en lo fundamental se actuó en apego a la realidad circundante, tanto en el plano nacional como internacional.

\section{UN PARTIDO ENRAIZADO CON LA REALIDAD NACIONAL}

Como es comprensible, después del resultado de la Guerra Civil de 1948 y de las políticas represivas ejercidas por la clase económicamente dominante, representadas en las distintas fracciones político-electorales y en un contexto internacional, caracterizado por la Guerra Fría, la tarea de reconstruir el Partido Vanguardia Popular fue harto difícil, aunque no imposible.

Incluso, desde la Penitenciaría Central, aplicando aquella tesis leninista de "audacia, audacia y más audacia”, la dirigencia nacional que estaba ahí detenida se las ingenió para redactar el periódico TRABAJO, sacarlo clandestinamente y editarlo, de modo que, la militancia que estaba también clandestina, lo hiciera circular ante sectores del pueblo costarricense, aunque debe tenerse en consideración lo extremadamente difícil de la situación política del país, y de hacer llegar un instrumento fundamental como es a prensa revolucionaria. Eso demostraba de una u otra manera, que el Partido estaba vivo, que había un nivel de energía por volver a reconstruirlo, a pesar de lo complejo y difícil de esta. 
Fue así como la Dirección Política, se planteó la tarea de integrarse al trabajo sindical, campesino, juvenil, femenino, comunal.

Vale decir, el Partido Vanguardia Popular fue de modo paulatino pero persistente, construyendo un tejido social, el cual le permitiera en el corto o mediano plazo insertarse de lleno en la vida política nacional.

Se desarrolló un arduo trabajo en las zonas bananeras, y ya para el año 1953 la Confederación General de Trabajadores Costarricenses, logró un importante auge de sus sindicatos promoviendo la concertación de una serie de Convenios Colectivos de Trabajo. Se plantearon conflictos colectivos durante el año 1957 en los Talleres de Zapatería Récord, Rojas, Ltda., Zapatería Molina, Zapatería Reyes, Fábrica de Zapatos Lux. En el sector bananero, se dio una gran lucha por el pago del aguinaldo, incluso, se produjo una huelga de gran envergadura, ello en razón de que la Compañía Bananera se negó a pagar el décimo-tercer mes; esta ha sido una de las huelgas más grandes y mejor organizadas en la historia del movimiento obrero de Costa Rica, la huelga triunfó y en esta lucha los trabajadores pusieron de manifiesto un alto grado de conciencia revolucionaria y un ejemplar espíritu de disciplina y de organización. La unidad en la acción practicada sin reservas por afiliados y dirigentes, creó las condiciones propicias para que luego se sellara la unidad orgánica de los sindicatos bananeros, así surgió la Federación Unica de Trabajadores Bananeros. Este paso representó un importante triunfo del movimiento obrero y del Partido Vanguardia Popular, principal propulsor de la unidad sindical (17).

Otro escenario en el que Vanguardia Popular trabajó en aras de ganar más espacio político, fue el comunal, lo hizo a través de las denominadas Juntas Progresistas, las cuales nacieron espontáneamente de diversas barriadas y comunidades, el Partido reconoce que: "Fue un gran acierto nuestro el haber descubierto las grandes posibilidades de movilización popular contenidas en estas organizaciones creadas espontáneamente por nuestro pueblo. A través de las Juntas Progresistas nuestro Partido y sus militantes jugaron un papel de vanguardia en una serie de importantes luchas populares, de profundo contenido progresista y antiimperialista. Las Juntas Progresistas son por su carácter una importante polea de transmisión, para llevar la energía 
revolucionaria de los comunistas a las grandes masas del pueblo. Aquí reside su importancia. Esta importancia se aumenta si tomamos en cuenta el carácter unitario de estas organizaciones” (18).

Un sector social al que se le dio importancia en la vida partidaria, fue a la juventud de educación secundaria y universitaria, de ahí que se hicieron todos los esfuerzos por incorporar jóvenes que asimilaron las tareas revolucionarias, se hizo un esfuerzo por crear la Federación de Estudiantes de Secundaria y un núcleo en la Universidad de Costa Rica. Las tareas se concretaron incidiendo en la formación de gobiernos estudiantiles sobre todo en las áreas del Valle Central.

A nivel universitario se creó el Frente de Acción Universitaria (F.A.U.), este se planteó las tareas de democratizar el proceso de elecciones para elegir los dirigentes de la Federación de Estudiantes de la Universidad de Costa Rica, vale decir, establecer el voto directo; por otra parte se formuló un Programa de reivindicaciones para el estudiantado, entre ello la necesidad de construir pasillos techados, mejoramiento del sistema de becas, necesidad de un comedor estudiantil, ampliación de compras de textos y una política de préstamos de libros, la cual permitiera más posibilidades de estudio para los jóvenes.

El Frente de Acción Universitaria tuvo su propio órgano de prensa, Periódico UNIDAD, a través del cual difundió las tesis de los comunistas dentro de la Universidad de Costa Rica.

Cabe destacar en este apartado que muchos de los jóvenes militantes del contingente universitario, con el paso de los años, se incorporaron al Partido, donde ocuparon puesta de Dirección a nivel de la Comisión Política, Comité Central, Comisiones Auxiliares y dirigencias regionales, entre ellos figuraron Oscar Madrigal Jiménez, Luis Orlando Corrales López, César Olivares, Ricardo Araya Montero, Manuel Delgado Cascante, Franklin Carvajal Bejarano, Beatriz Ferreto López, María Elena Guadrón.

En otro orden, hay que destacar el trabajo partidario con el campesinado, este aunque no fuera tan sólido se fue fraguando en las localidades de Santa Bárbara, Barva, Río Cuarto, Los Chiles, San Carlos, Turrúcares, Orosi, Cervantes, Turrialba, Nicoya, Ortega y Las Juntas, La 
Cruz, Pacuarito, Ramal del Carmen, de igual forma en Osa, Golfito y Aguirre. Aunque débiles orgánicamente, sí jugaron un papel importante en el proceso de acumulación de fuerzas, que era parte de la táctica del Partido Vanguardia Popular.

Un sector social en el que los comunistas, no pudieron hacer un trabajo efectivo de afiliación y organización fue con el naciente proletariado industrial, producto de la inserción de Costa Rica al Mercado Común Centroamericano.

Lleva razón, la historiadora Marielos Aguilar, cuando afirma que "A los nuevos contingentes de obreros les costó mucho asimilar la necesidad de su organización. Las primeras expectativas que despertó el trabajo en la fábrica, constituyeron un elemento adverso para el surgimiento de la organización laboral en el sector industrial, pues los nuevos obreros esperaban que las labores fabriles por sí mismos, les permitieran alcanzar un mejor nivel de vida. En el caso de los obreros de origen rural el solo hecho de trasladarse a la ciudad, los hacía suponer que el disfrute de los servicios ofrecidos aquí los haría mejorar sus condiciones generales de vida. De tal manera, que el llamado de las dirigencias sindicales para organizar a esos nuevos obreros industriales, no tuvo mayores efectos, en el corto plazo” (19).

Este repaso, nos da una idea de que el Partido Vanguardia Popular hizo lo que estuvo a su alcance, como es lógico con aciertos y errores, para compenetrarse en la cotidianidad del quehacer costarricense, y de esa forma ir ganando la conciencia democrática y revolucionaria de la clase trabajadora.

Sin temor a equivocarnos, podemos afirmar que el Partido Vanguardia Popular, actuó acorde con base en los principios leninistas, los cuales entre otros aspectos advierten: "Solo en nombre de un verdadero partido obrero podremos sin perder la fidelidad a nuestras convicciones, exhortar a todos los elementos progresivos del país a desplegar una actividad revolucionaria, exhortar a apoyar el socialismo a todos los trabajadores, a todos los dolientes y oprimidos" (20). 


\section{EL CONTEXTO INTERNACIONAL Y LAS VÍAS DE LA REVOLUCIÓN}

Cuando un partido comunista, se inserta en la lucha social de lleno, tiene que plantearse un sinnúmero de aspectos, y resolverlos de la mejor manera, para cumplir las tareas con creces.

De manera autocrítica, el Partido Vanguardia Popular, en el IX Congreso (Abril 1962), se planteó: "Nuestro Partido, en el período anterior al 48, perdió la perspectiva del Poder, no se planteó seriamente la cuestión de la lucha por él”, y agrega: “En síntesis, ningún Partido Comunista debe nunca olvidar que el problema cardinal de la Revolución es la cuestión del Poder” (21).

Pero debe advertirse, que para plantearse la cuestión cardinal de la toma del Poder, necesariamente debe hacerse un exhaustivo análisis del contexto internacional, del nivel de la correlación de fuerzas y con extrema seriedad, definir cuál es la vía o las vías de la revolución, para el logro de ese objetivo estratégico.

Trataremos de hacer mención a un conjunto de elementos que giraron en la palestra internacional, desde la finalización de la Guerra Civil de 1948, hasta el momento en que el Partido Vanguardia Popular participa en la contienda electoral de 1970, con el nombre de Partido Acción Socialista (PASO).

1- $\quad$ Ya en 1949, el Partido Comunista de China triunfa, y se inicia la Revolución China, que tuvo como baluarte fundamental al campesinado. Los revolucionarios chinos tuvieron la capacidad teórico-práctica de poder hacer una lectura precisa y correcta que les permitiera dar las luchas necesarias para tomar el Poder.

2- $\quad$ Ya en el primer lustro de la década de los años cincuenta, el campo socialista había podido consolidarse, recuérdese que en un primer momento esos países de Europa del Este, se autodenominaron Democracias Populares; y la Unión Soviética, con gran esfuerzo y sacrificio construía los cimientos de una revolución socialista, pero no podemos obviar que en estos países, no existían las condiciones objetivas y subjetivas suficientemente 
maduras para poner en práctica un proyecto revolucionario, donde la clase obrera y el campesinado, fueran realmente las fuerzas motrices para emprender desarrollar la revolución socialista.

La debilidad de desarrollar estos proyectos socialistas en Europa del Este, debe explicarse también que ello fue el producto de una imposición de Stalin en la Conferencia de Yalta, cónclave en donde los llamados Tres grandes, Franklin Delano Roosevelt, Winston Churchil, Josef Stalin, se repartieron el mundo en áreas de influencia.

A pesar de lo anterior, hubo un esfuerzo por forjar la comunidad socialista y enfrentar de manera decidida al imperialismo norteamericano, quien después de la Segunda Guerra Mundial, se convirtió en el gendarme del Sistema Capitalista Mundial.

3- Aquí en Centroamérica, se llevaba a cabo un proyecto revolucionario, concretamente en Guatemala, pero cuando el Presidente Jacobo Arbenz anunció la promulgación de una reforma agraria, la United Fruit Co., quien se veía afectada por tal medida "Más del 15\% de las 263.000 hectáreas que aproximadamente poseía la UFCO tenían que expropiarse con el pago de una compensación que se calcularía basándose en la declaración de impuestos que la compañía hiciera en 1950 ... la UFCO logró que gran parte de la prensa norteamericana hiciera causa común con ella ... reforzada por el histérico ambiente político del período de McCarthy, durante la cual la lógica del anticomunismo lo abarcaba todo ... la invasión a Guatemala se concretó en junio de 1954 bajo el mando del coronel Castillo Armas, él fue el firme candidato de los norteamericanos a la presidencia, tomó posesión del cargo y empezó el desmantelamiento exhaustivo de las reformas que se habían llevado a cabo en el decenio precedente” (22).

4- Hubo un acontecimiento de gran repercusión mundial, en el año 1956, nos referimos al XX Congreso del Partido Comunista de la Unión Soviética, en dicho evento, el Secretario General del PCUS, Nikita Khrushchev, presentó lo que se conoce como el Informe Secreto, este documento es una crítica acerca del dirigente soviético Stalin, el documento apunta: “Después de la muerte de Stalin, el Comité Central del Partido comenzó a estudiar la 
forma de explicar de modo conciso y consistente, el hecho de que no es permitido y de que es ajeno al espíritu del marxismo-leninismo elevar a una persona hasta transformarla en un superhombre, dotado de características sobrenaturales semejantes a las de un dios ... Stalin, utilizando su poder ilimitado cometió muchos abusos en nombre del Comité Central, y sin consultar la opinión de los miembros del Comité o siquiera a los miembros del Buró Político; con frecuencia no informaba acerca de sus decisiones personales respecto a asuntos muy importantes del Partido y del Gobierno ... En la práctica, Stalin ignoraba las normas de la vida del Partido y pisoteaba los principios leninistas de gobierno colegial ... El XX Congreso del Partido Comunista de la Unión Soviética, pone de manifiesto con nuevo vigor la inquebrantable unidad de nuestro Partido y su cohesión en torno al Comité Central, como también su decisión de lograr la culminación de su gran tarea que es construir el comunismo ... Tenemos la seguridad más absoluta de que nuestro Partido, fortalecido por las históricas resoluciones del XX Congreso, conducirá al pueblo soviético por la senda leninista hacia nuevos éxitos y nuevas victorias” (23).

5- $\quad$ En los últimos años de la década de los cincuenta, la Unión Soviética demostró al mundo, su capacidad científica-tecnológica, inició la carrera espacial, aparte de satélites, envió al primer ser humano al cosmos, y es así, como con el cosmonauta Yuri Gagarin cumplió victorioso esa tarea. La Unión Soviética, había adquirido el nivel de super-potencia, su desarrollo sostenido así lo demostraba. Pero precisamente, ese carácter de superpotencia lo convierte en un Estado Socialista, que usa todos los métodos a su alcance para que el Movimiento Comunista Internacional, avale sus tesis en política exterior, básicamente aquella, de que los partidos comunistas debían adoptar una "línea democrática nacional”, de "frente unido con la burguesía", una vía pacífica, que fue avalada por el Partido Comunista Colombiano en su IX Congreso de 1962; del Partido Comunista Boliviano en 1964; donde se plantea que la vía pacífica es considerada como la más probable; el Partido Comunista Brasileño, el cual bajo la influencia de la desestalinización, efectúa en 1958 la Declaración donde llama a los comunistas a formar el Frente Unido Nacionalista y Democrático, cuya dirección recaía en manos de la burguesía nacional (24).

6- El tradicional esquema marxista-leninista, recibe una profunda llamada de atención, 
empezando el año 1959. Ese día fue el inicio del triunfo de la Revolución Cubana que vino a cambiar el destino político de los pueblos de América Latina y del mundo subdesarrollado.

La tesis fundamental de la dirigencia cubana, es que el camino más acertado para lograr el triunfo, es la vía armada. Ernesto Che Guevara, dirigente de esa revolución, lo plantea en los términos que siguen: "El pueblo de Cuba frente a la agresión sabe elegir su camino de sacrificio, de sangre, de dolor, pero de victoria ... hemos demostrado que un grupo pequeño de hombres decididos apoyados por el pueblo y sin miedo a morir si fuera necesario puede llegar a imponerse a un ejército regular, disciplinado y derrotado definitivamente. Esa es la enseñanza fundamental ... se está defendiendo más que una causa nacional, se está defendiendo la causa entera de América, se está mostrando a los pueblos de todo el Continente lo que puede hacer un pueblo cuando está unido ... La guerra de guerrillas no es como se piensa, una guerra minúscula, una guerra de un grupo minoritario contra un ejército poderoso, no; la guerra de guerrillas es la guerra del pueblo entero contra la opresión dominante ... La unidad es un factor preponderante de la lucha revolucionaria” (25).

Este hecho histórico fue determinante porque hizo pensar y repensar a los revolucionarios latinoamericanos, muchos de los cuales abandonaron la izquierda histórica tradicional de los Partidos Comunistas, y se inclinaron por las tesis de la vía armada, utilizando los métodos de guerra de guerrillas, foco guerrillero, guerra popular prolongada, guerrilla urbana, guerrilla rural.

Personas que ocupaban puestos de Dirección Política en los Partidos Comunistas, como Salvador Cayetano Carpio, Secretario General del Partido Comunista de El Salvador, Douglas Bravo, Teodoro Petkoff, del Partido Comunista de Venezuela; Carlos Marighella miembro de la Dirección del Partido Comunista de Brasil y muchos más, pasan a integrarse a la lucha armada, en razón de que consideran que esa es la única vía posible de derrotar a la burguesía y al imperialismo. 
Marighella por ejemplo señaló: "La revolución estaba por tanto a la orden del día. Se trataba de elaborar una estrategia global partiendo de la premisa de la necesidad de la lucha armada ... no pretendíamos ser los dueños de la revolución, sino simplemente cumplir con nuestra obligación revolucionaria” (26).

Durante la década de los años sesenta, surgieron una considerable cantidad de grupos armados revolucionarios a lo largo y ancho de toda América Latina, a ellos la izquierda tradicional les impuso el mote de ultraizquierdistas; el debate fue arduo y profundo tanto en el seno de los partidos comunistas, como en eventos internacionales convocados para discutir sobre este aspecto, tales como las Conferencias de OLAS (1965) (Organización Latinoamericana de Solidaridad) y la Conferencia Tricontinental, ambas celebradas en La Habana, Cuba, y ahí se reafirmaron las tesis de la vía armada.

Pocas fueron las organizaciones que plantearon la vía pacífica o no armada, entre ellas, el Partido Comunista de Chile, quien en el XII Congreso de marzo de 1962, planteó: "La tesis sobre la vía pacífica no es una forma táctica, sino una proposición ligada al programa mismo del movimiento comunista. La vía pacífica corresponde enteramente al interés de la marcha hacia el socialismo y al carácter eminentemente humanista de la teoría marxista-leninista. La actual correlación de fuerzas nacional e internacional ha creado un aumento de posibilidades para conducir la revolución sin lucha armada” (27).

Otro caso fue precisamente el del Partido Vanguardia Popular de Costa Rica, por medio de su Secretario General, Manuel Mora Valverde, manifestó: “Estamos decididos a defender el régimen democrático de nuestro país y a luchar por ampliarlo. Creemos que es posible que la organización social se transforme en Costa Rica sin necesidad de recurrir a la guerra civil y haremos todo cuanto esté a nuestro alcance para evitarle a nuestro pueblo sacrificios innecesarios" y años más tarde agregó: "Nuestro conocimiento del país, de sus tradiciones, de las características de su economía, de la índole y mentalidad del pueblo, del origen y evolución de sus instituciones políticas nos ha llevado a la conclusión de que en nuestro país es posible avanzar hacia el socialismo por vía pacífica” (28). 
7- $\quad$ Otro acontecimiento, que no puede obviarse al analizar el contexto internacional y las vías de la revolución, en el que tuvo que desenvolverse la praxis del Partido Vanguardia Popular, fue el denominado conflicto Chino-Soviético. Nos narra don Jaime Cerdas Mora, miembro de la Comisión Política del Partido Vanguardia Popular quien en 1957 asistió a la Unión Soviética, pues “En Moscú se celebraba la famosa reunión de 1957, primer encuentro del movimiento comunista internacional después de la guerra. La importancia del evento fue realzada aún más con la visita de Mao Tse Tung ... En particular, me asombró que se quisiera poner al PCUS como jefe y guía no solo en la política mundial sino en cuestiones regionales, en las que a mi juicio era a los partidos locales a quienes por obligación les correspondía un mayor conocimiento ... después de una cena en el Kremlin, Mao pidió saludar personalmente a las delegadas latinoamericanos y nos invitó a visitar China ... La racionalización de las experiencias que hacían los chinos me parecía de una profunda sabiduría. Su concepción de la construcción del Partido, de la incorporación orgánica del militante a través de su transformación ideológica; su manera de entender y practicar el frente único, de llevar adelante la crítica y la autocrítica, todo eso lo sacaban de la práctica concreta, a la que seguía una evaluación racional y equilibrada. "Aprender de los propios errores"; “aprender del maestro negativo”, eran consignas siempre en labios de los chinos ... Sin pensarlo dos veces lo interrumpí para preguntarle en qué quedaba entonces el movimiento por lo que estábamos impulsando por todos lados ... Mao la tomó de base para redefinir las tareas del movimiento por la paz. La forma en que lo hizo, ya en ese momento muy distinta a la que defendían los soviéticos. Pero jamás en aquel momento podíamos imaginarnos el conflicto chino-soviético de los años sesenta" (29).

Sobre este tema tan candente, el destacado dirigente comunista italiano Palmiro Togliatti, apuntó: "Creo que puede afirmarse, sin temor a equivocarse, que la desenfrenada y vergonzosa campaña china en contra de la Unión Soviética, el PCUS, sus dirigentes y en modo especial al camarada Jruschov, no ha tenido entre las masas consecuencias dignas de gran relieve, no obstante que sea explotada a fondo por las propagandas burguesas y gubernamentales. La autoridad y el prestigio de la Unión Soviética entre las masas continúan siendo enorme. Las más groseras calumnias chinas no tienen ningún arrastre 
... Lo que preocupa a las masas y también a una parte no indiferente de los comunistas es el hecho en sí del conflicto tan agudo entre dos países que se han vuelto ambos socialistas a través de la victoria de dos grandes revoluciones. Este hecho pone a discusión los principios mismos del socialismo y nosotros debemos hacer un gran esfuerzo para explicar cuáles son las condiciones históricas, políticas, de partido y personales que han contribuido a crear el conflicto" (30).

8- $\quad$ En medio de la complejidad, tanto del sistema capitalista y del sistema socialista, en el período que estamos estudiando, no se puede obviar el hecho histórico que conocemos como la Guerra de Viet Nam, esa agresión brutal y despiadada por parte del gobierno de Estados Unidos de América, contra un pueblo humilde a más de 17.000 kilómetros de sus fronteras. Al igual que en el resto del mundo, el Partido Vanguardia Popular en Costa Rica, al lado de otras organizaciones gremiales y personalidades del ámbito cultural e intelectual, se sumaron a la solidaridad militante con el pueblo vietnamita y ello jugó un papel importante en forjar una conciencia antiimperialista en sectores de la población costarricense. Viet Nam, fue un paradigma de cómo se lucha contra el imperialismo, aún en condiciones adversas. Ya el dirigente máximo, Ho Chi Minh, había puntualizado: "Solo la clase obrera puede demostrar la mayor valentía, la mayor firmeza revolucionaria y es capaz de enfrentar siempre con tenacidad a los imperialistas y colonialistas ... A la luz del marxismo-leninismo, nuestro partido logró, a pocos días de fundado, concebir de manera integral el camino del desarrollo necesario de la revolución vietnamita. En las tesis políticas de 1930, se señaló claramente que la revolución vietnamita pasaría por dos etapas: primero llevar a cabo la revolución nacional democrática y luego avanzar directamente a la revolución socialista ... El triunfo de la revolución vietnamita es el triunfo del marxismo-leninismo aplicado de manera creadora en las condiciones de un país colonial y semifeudal. Nuestro pueblo se siente sumamente orgulloso de ser el combatiente en la primera línea de lucha de los pueblos del mundo contra el imperialismo norteamericano" (31).

9- $\quad$ Debe señalarse, que la lucha de clases a nivel mundial, en lo medular se situaba en el enfrentamiento de dos regímenes sociales antagónicos. Es esta perspectiva que debemos 
ubicar históricamente las luchas estudiantiles del año 1968, en varias latitudes del mundo, esto es, París 68, momento en que las luchas de masas del estudiantado francés, estuvieron a punto de derrocar al gobierno del General Charles De Gaulle; en otro escenario, esta vez en Berkeley, en ese mismo año, la juventud universitaria se declaró en lucha permanente por los derechos civiles y contra la agresión del imperialismo estadounidense al pueblo de Viet-Nam; por otra parte, el estudiantado de secundaria y universitario de la ciudad de México, se tomó las calles y protestó por las políticas antiestudiantiles y antipopulares del gobierno presidido por Gustavo Díaz Ordaz; la clase dominante mexicana para impedir el ascenso de la lucha popular, sin ningún reparo desató la Masacre de Tlatelolco, concretamente en el lugar llamado Plaza de las Tres Culturas. Estos hechos, pusieron de manifiesto que existía un alto grado de conciencia antiimperialista, pero lo más significativo fue - y es digno de ser estudiado con mayor profundidad - que el sector social que vanguardizó estas jornadas de lucha fue la juventud estudiantil, obviamente no la clase obrera, ni el campesinado como se podría pensar desde una perspectiva sectaria y dogmática.

Pero no solo dentro del sistema capitalista, "la cosa estaba color de hormiga", sino que la ola de cambios con perfiles democráticos, también azotaba al llamado campo socialista de Europa Oriental.

Durante el año 1967 y primeros meses del ‘68, la Dirección Política del Partido Comunista de Checoeslovaquia, se propuso llevar a la práctica una serie de medidas para democratizar la sociedad, esto es, ampliar y profundizar el régimen socialista, y no seguir el modelo tan rígido que imponía el Partido Comunista de la Unión Soviética. Esas intenciones de la Dirección del Partido Comunista Checoeslovaco, tropezaron con la decisión del Pacto de Varsovia quien intervino para aplicar "la defensa del socialismo real”.

Ante este hecho, el Partido Vanguardia Popular, se pronunció a favor de la conducta asumida por la Dirección del Partido Comunista de la Unión Soviética y del Pacto de Varsovia, se alegó entre otras cuestiones lo que sigue: "Era necesario entrar a Chevoeslovaquia antes de que este país fuera ocupado por los militares alemanes y yanquis. De esta manera 
se conseguían tres cosas: a) se defendería la independencia del pueblo checo; b) se les cerraría a los ejércitos del imperialismo, la puerta de entrada al mundo socialista; y c) se eliminaría un serio peligro de guerra mundial. Tal es el significado de la entrada de los ejércitos del Pacto de Varsovia a Checoeslovaquia” y se agregaba: "Los ejércitos socialistas no entraron a Chevoeslovaquia para arrebatarle al pueblo checoeslovaco su independencia, ni sus riquezas” (32).

Por otra parte, la Dirección del Partido Comunista de la Unión Soviética, estaba convencida que ese país estaba listo para emprender la construcción de la sociedad comunista, pues durante los cincuenta años anteriores con gran esfuerzo se habían cumplido las etapas de la construcción de una sociedad socialista, (recuérdese que la escuela estalinista, había creado la concepción de que las revoluciones se hacían por etapas y ellos mismos no escapan a ese criterio dogmático y sectario).

Leonid Brezhnev, Secretario General del Partido Comunista de la Unión Soviética, en el acto de celebración de los Cincuenta Años de la Revolución Bolchevique, enfatizó: “A comienzos de los años 60, el país soviético entró en una nueva fase: emprendió la construcción desplegada la sociedad comunista ... El XXIII Congreso del PCUS, sintetizó la experiencia adquirida por el partido en los años precedentes y trazó las vías concretas del desarrollo de nuestra sociedad. El tercer Programa del Partido, el programa de la construcción de los fundamentos de la sociedad comunista también será cumplido; ¡La Unión Soviética, la Patria del socialismo, será del mismo modo la Patria del comunismo en la Tierra!” (33). 


\section{EL PROCESO DE INSCRIPCIÓN DEL BLOQUE DE OBREROS, CAMPESINOS E INTELECTUALES}

Una característica, que se aprecia en toda la documentación que hemos trabajado, cuando hacemos una investigación de carácter histórico sobre el Partido Vanguardia Popular, es el esfuerzo del trabajo conjunto, el cual se distingue desde las decisiones de Comisión Política, Comité Central, Comités Regionales, Comisiones Auxiliares, hasta la Célula, o sea, que hay una disciplina partidaria en toda su estructura orgánica.

Lleva razón, Manuel Mora Valverde, cuando expresó: “El trabajo de nuestro Partido ha sido siempre un trabajo colectivo. La unidad en la Dirección y la unidad en la acción han sido las mejores armas de nuestra lucha. Es muy difícil juzgar el trabajo y los méritos de un miembro de nuestra dirección separándolo del trabajo colectivo” (34).

Una de esas decisiones colectivas, asumidas por el Partido Vanguardia Popular, fue la de trabajar para inscribir de cara al proceso electoral de febrero de 1970,con un proyecto político electoral, al cual se le denominó Bloque de Obreros, Campesinos e Intelectuales.

Se cumplió con los requisitos y trámites pertinentes, de ahí que el "Registro Civil, Departamento Electoral, San José, a las quince horas y treinta minutos del 27 de diciembre de 1968. En las presentes diligencias del señor Manuel Mora Valverde, mayor, casado, abogado, cédula de identidad 1-076-4103, en su carácter de Presidente del Comité Ejecutivo Nacional del Partido Bloque de Obreros, Campesinos e Intelectuales, solicita la inscripción de éste en escala nacional para participar en las próximas Elecciones Generales ... d) Que las adhesiones presentadas y examinadas tres mil cuatrocientas cincuenta y cuatro, corresponden a ciudadanos portadores de cédula de identidad inscritos como electores en el Padrón Nacional que lleva esta oficina (ver folios 17 y 22" (35).

De modo inmediato, los sectores más conservadores, conspicuos representantes de la oligarquía nacional, representados por el señor Frank Marshall, Presidente del Partido Unión Cívica Revolucionaria, pidieron al Registro Electoral que no sea inscrito el Bloque de Obreros, 
Campesinos e Intelectuales, que encabeza el Lic. Manuel Mora Valverde; el Partido del señor Marshall sostiene que: "la inscripción de ese partido pondría en peligro el régimen democrático costarricense ... esgrimió las siguientes razones concretas: que el Partido cuya inscripción objeta ha sido ya puesto fuera de ley lo cual ofrece probar, que los dirigentes de este Partido son conocidos comunistas y que por serlo no tienen derecho a constituir un partido para intervenir en las elecciones; y que las firmas contenidas en los pliegos de adhesiones son falsas y deben ser investigadas de previo" (36).

El Partido Vanguardia Popular, desplegó un amplio trabajo en el seno de la sociedad costarricense, en aras de ganar el apoyo para su causa, pero eso sí, debe advertirse que dicho partido no tenía como eje conductor el trabajo electoral, sino que su quehacer se fundamentaba en afilar y organizar personas para construir una vanguardia del pueblo de carácter revolucionaria, y para ello había incursionado en el proletariado bananero, campesinado de diversos lugares del país, con la sociedad civil en luchas comunes para mejorar su nivel de vida, con la juventud, concretamente en los centros educativos de secundaria y en la Universidad.

Lo anterior, porque la tesis política central del Partido Vanguardia Popular, era crear un Frente Democrático, Agrario, Popular y Antiimperialista, el cual cumpliera tareas democráticas y revolucionarias que abrieran paso a la construcción de una sociedad socialista.

Obvio es comprender, que el interés de participar en las elecciones nacionales, era precisamente para, en primer lugar llevar ese mensaje al pueblo costarricense, y elegir diputados y regidores, que desde sus puestos coadyuvaron a denunciar las lacras del sistema capitalista, y, también presentar propuestas, todo ello en un proceso dialéctico de forma y contenido, de ir de lo simple a lo complejo, e ir desarrollando con nuevos ímpetus un proceso de acumulación de fuerzas mediante el cual se pudiera materializar la idea de hacer avanzar la revolución en Costa Rica, todo ello, por la vía pacífica, como de modo claro, lo estableció el IX Congreso del Partido Vanguardia Popular en 1962, en las resoluciones se planteó de modo enfático, lo siguiente: "Pero debemos mostrar una gran flexibilidad y objetividad, esforzándonos porque los prejuicios no nos nublen la razón... El Partido de la clase obrera debe dar muestras siempre de una gran sensibilidad política, gran capacidad de maniobra, gran capacidad para captar y comprender 
los fenómenos nuevos que se presentan ... Nuestro Partido ha defendido ya su táctica general de lucha. Estamos por la lucha pacífica, por el respeto del orden constitucional y de las armas legales de lucha” (37).

Debe tenerse en consideración, y ubicar correctamente, que cuando una organización revolucionaria, participa en una contienda electoral, lo hace teniendo en cuenta, que esto es una faceta de la lucha de clases, la cual en lo fundamental, se expresa en términos ideológicos.

A pesar de que el Bloque de Obreros, Campesinos e Intelectuales, presento todo a derecho de acuerdo con la normativa legal en materia electoral, el Tribunal Supremo de Elecciones argumenta que de acuerdo a la Ley No. 1191 no se puede inscribir a dicho Partido; el Partido en mención replica señalando que "La Ley No. 1191, está derogada por el artículo 57 del Código Electoral. Este Código se promulgó por última vez en marzo de 1952 y necesariamente dejó sin efecto la mencionada ley, que había sido promulgada dos años antes” (38).

Pero la actitud de intransigencia del Tribunal Supremo de Elecciones, no mermó en absoluto, en razón de que "Continuando en su trayectoria de arbitrariedades el Tribunal Supremo de Elecciones han negado personería legal al Bloque de Obreros, Campesinos e Intelectuales para hacer consultas... En suma, que el Tribunal se declaró incompetente para poner fuera de Ley al Bloque de Obreros, Campesinos e Intelectuales por considerar, que esto es resorte de la Asamblea Legislativa, y por otra parte, pretende que la inscripción del mismo resuelta favorablemente por Registro Civil no está en firme" (39).

Ante esta arremetida del Tribunal Supremo de Elecciones, el Secretario General del Partido Vanguardia Popular, Manuel Mora Valverde, le envió una carta pública a don José Figueres Ferrer, nótese que dice: carta pública a don José Figueres, en la cual expresa: "Yo, por mi parte, le hablo como Presidente del Bloque de Obreros, Campesinos e Intelectuales ... Como usted sabe está planteada en estos momentos una lucha alrededor de la legalidad de mi Partido. Las fuerzas más reaccionarias del país, y las personas y organizaciones interesadas en obtener del Estado concesiones y contratos sucios, sin la presencia en la Asamblea Legislativa de representantes de la izquierda nacional, se han confabulado contra nosotros y luchan porque 
se nos ilegalice ... Su Partido, señor Figueres, tiene en sus manos la suerte del Bloque, porque controla la mayoría de la Asamblea Legislativa y es la Asamblea la encargada por la Constitución de resolver este problema ... Podría responderme usted, que yo no tengo derecho a pedir cuentas sobre la política de su Partido y que mi Partido no puede pretender que el suyo le garantice la legalidad. En efecto, ustedes y nosotros siempre hemos estado frente a frente desde 1948, cuando nos batimos en una guerra civil sangrienta y dolorosa. ¿Pero no están proclamándose ustedes abanderados de la Democracia? ¿No han dicho una y mil veces que defenderán con todas sus fuerzas y sin escatimar sacrificios la libertad de elegir? Sería absurdo que esa libertad de elegir de que ustedes hablan fuera únicamente la de ustedes. Esa no puede ser la actitud de un Partido que se dice de principios. Si ustedes son un Partido de principios, cualquier ciudadano, adversario o no adversario de ustedes, tiene derecho a exigirles que sean consecuentes con esos principios ... En mi concepto hay algo más importante, que es un compromiso sellado con sangre ... Yo le pido que se apoye en su Partido que es democrático casi en su totalidad y haga bueno el compromiso de Ochomogo que es un compromiso sagrado y profundamente democrático” (40).

De igual forma, Manuel Mora Valverde, emplazó al Dr. Rafael Angel Calderón Guardia, en los términos que siguen: "Me dirijo a usted por escrito en vista de que no es posible hacerlo de palabra. Y lo hago por medio de una carta pública para que nadie pueda mal interpretar mi mensaje ... Nuestra alianza fue clara y limpia de pecados políticos. Ni usted hizo una sola concesión de principios ni nosotros tampoco lo hicimos. No le exigimos ninguna prebenda, ni siquiera un modesto puesto público ... Solo dos cosas le exigimos: que limpiara su Gobierno de personas señaladas por el pueblo como responsables principales de los errores cometidos, y que gobernara, durante los dos años que le quedaban de administración, para el pueblo y no para los poderosos. Usted prometió y cumplió. Depuró el gobierno hasta donde pudo y orientó la acción del Estado hacia la reforma social ... No fue por capricho, ni por ingenuidad que usted se alió con nosotros. Se alió porque comprendió que nuestro apoyo le era útil en momentos en que su Gobierno estaba a punto de derrumbarse. Y no se equivocó ... La guerra civil fue la culminación de la campaña de odios que durante varios años se mantuvo contra usted y contra nosotros. En esa guerra nos corrimos la misma suerte los calderonistas, los comunistas, usted y yo. Terminada la guerra vinieron las represalias y una de esas represalias fue el párrafo segundo 
del artículo 98 de la Constitución ... Pero a pesar de que somos marxistas, y por lo tanto realistas conocedores del alma humana, nunca ha dejado de dolernos y de indignarnos que nuestros aliados de ayer sean nuestros verdugos de hoy ... Hace una semana le dirigí una carta abierta a don José Figueres reclamándole el cumplimiento del Pacto de Ochomogo. Ahora le dirijo esta a usted reclamándole el cumplimiento de un pacto de honor al cual nosotros siempre supimos responder con lealtad, incluso cuando fue necesario que derramáramos nuestra sangre por defender las conquistas sociales y con ellas su presidencia ... Estoy defendiendo legítimos derechos de mi Partido y una de las más importantes conquistas democráticas del pueblo costarricense” (41).

Por otra parte, el Lic. Eduardo Mora Valverde, Candidato Presidencial del Bloque de Obreros, Campesinos e Intelectuales, en un discurso radial y luego transcrito en el periódico Libertad, apunto: "Nuestro partido, el Bloque de Obreros, Campesinos e Intelectuales, es el partido de la clase obrera, es el partido de los campesinos, es el partido de los intelectuales ... En fin nuestro Partido, es el partido de las amplias masas populares que necesitan y se incorporan cada vez con mayor conciencia al proceso revolucionario ... Queremos que se construya un Gobierno Popular por su extracción nacional, por su carácter democrático, por su contenido antiimperialista ... Por eso concebimos a ese gobierno como el más democrático de todos los que haya tenido Costa Rica.... Hemos dicho varias veces y lo hemos dicho con énfasis tal, y como siempre planteamos nuestros puntos de vista, que todo esto lo podemos alcanzar sin necesidad de emplear la violencia armada. Somos enemigos de la violencia armada, no tanto por nosotros mismos, sino por el dolor que ello causaría a los hogares costarricenses, al pueblo en general ... Queremos respetar el espíritu civilista y altamente democrático de los costarricenses, y hemos elaborado nuestro programa y trazado nuestra línea táctica y estratégica respetando los sentimientos de nuestro pueblo" (42).

La lucha por el derecho de los comunistas a participar en el proceso electoral, conmovió la conciencia democrática de miles de costarricenses, y es notorio destacar, la actitud y manifiesto de un selecto grupo de intelectuales, de las más diversas áreas del conocimiento, en esta lucha por defender y ampliar el régimen democrático: "Premios Nacionales Exigen Libertad Electoral: Consideramos que la libertad de sufragio es sustento del régimen democrático y de la paz 
nacional. Nadie debe tener el derecho a vulnerarla. No se debe lanzar al ostracismo electoral a ningún partido sea de derecha, del centro o de la izquierda. Creemos con toda firmeza que las ideas no pueden ni deben ser perseguidas.

\begin{tabular}{|l|c|c|}
\hline \multicolumn{1}{|c|}{ NOMBRE } & DISCIPLINA & $\begin{array}{c}\text { AÑO DE } \\
\text { OTORGAMIENTO }\end{array}$ \\
\hline Gilberto Bonilla R. & Premio Nacional Medicina & 1966 \\
\hline Néstor Zeledón & Premio Nacional Escultura & 1967 \\
\hline Alfonso Chase & Premio Nacional Poesía & 1968 \\
\hline Ricardo Blanco S. & Premio Nacional Historia & 1967 \\
\hline Benjamín Gutiérrez & Premio Nacional Música & $1961-1962-1964$ \\
\hline Juan Rafael Chacón & Premio Nacional Escultura & 1962 \\
\hline Carlos Salazar Herrera & Premio Nacional Literatura & 1964 \\
\hline Teodoro Ulate & Premio Nacional Ensayo & 1966 \\
\hline Carlos Meléndez & Premio Nacional Historia & 1966 \\
\hline Julieta Dobles I. & Premio Nacional Poesía & 1968 \\
\hline Rafael A. García & Premio Nacional Pintura & 1966 \\
\hline Isaac Felipe Azofeifa & Premio Nacional Poesía & 1964 \\
\hline Jorge Charpantier & Premio Nacional Poesía & 1968 \\
\hline Mario Picado & Premio Nacional Poesía & 1967 \\
\hline Hernán González & Premio Nacional Escultura & $1966-1968$ \\
\hline Víctor Ml. Arroyo & Premio Nacional Ensayo & 1967 \\
\hline Samuel Rovinski & Premio Nacional Cuento & 1968 \\
\hline Jorge Enrique Guier & Premio Nacional Historia & 1968 \\
\hline Margarita Bertheau & Premio Nacional Pintura & 1968 \\
\hline León Pacheco & Premio Nacional Ensayo & 1968 \\
\hline Constantino Láscaris & Premio Nacional Ensayo & 1966 \\
\hline Jorge Gallardo & Premio Nacional Pintura & 1966 \\
\hline
\end{tabular}

La presión de los sectores más recalcitrantes de la derecha costarricense, lograron que el Tribunal Supremo de Elecciones proscribiera al Partido Bloque de Obreros, Campesinos e Intelectuales. El vocero periodístico del Partido Vanguardia Popular, escribió: "Como es de conocimiento público, la Asamblea Legislativa devolvió al Tribunal Supremo de Elecciones el expediente sobre el Bloque de Obreros, Campesinos e Intelectuales, que el Tribunal por su parte le había enviado. El Tribunal revocó la resolución del Registro Civil que ordenaba la inscripción 
del Bloque. En otras palabras, resolvió que el Bloque no podía mantenerse inscrito porque sus asambleas provinciales resultaban nulas por haberse celebrado sin el quorum ordenado por la Ley y los Estatutos del Partido (44).

Refiriéndose al trabajo de recolección de firmas y a la ilegalización del Bloque de Obreros, Campesinos e Intelectuales, Manuel Mora Valverde, señaló: "Esas firmas, recogidas al cabo de 20 años de vida ilegal durante los cuales se nos ha privado de nuestra libertad de acción, no son simples trazos puestos sobre pliegos de papel: son reflejo claro de un estado de conciencia de nuestras masas populares. Para firmar por un Partido revolucionario, calumniado y bloqueado por las fuerzas del imperialismo y de la oligarquía, no basta saber firmar; es necesario, además, saber por qué y para qué se firma. Por tanto, esas firmas recogidas de casa en casa a lo largo y ancho del país ponen de manifiesto dos cosas: que nuestro pueblo se pronuncia por un cambio real y hondo en nuestra vida social, y que la lucha de nuestro Partido, desarrollada a lo largo de casi 40 años cuenta con la confianza y el apoyo de las masas" y por otra parte agregó: "Nos pusieron fuera de Ley porque luchamos por meter dentro de la Ley a sus grandes compañías y en primer lugar a la United Fruit Co. Nos pusieron fuera de Ley porque no les dejamos pasar una contratación petrolera, que era un asalto a los intereses económicos de nuestro pueblo. En resumen, que nos pusieron fuera de Ley porque nos negamos a vendérnosles y a traicionar al pueblo de Costa Rica” (45).

\section{SURGIMIENTO DEL PARTIDO ACCIÓN SOCIALISTA}

Ante el hecho real de la ilegalización del Bloque de Obreros, Campesinos e Intelectuales, surgió la propuesta de don Marcial Aguiluz Orellana Presidente del Comité Ejecutivo del Partido Acción Socialista, él planteó lo siguiente: "Es muy lamentable que el Tribunal se haya dejado sorprender por la matonería de grupos de carácter fascista, que hasta el momento no han dado ninguna demostración efectiva de respeto al régimen legal que vivimos ... El Partido Acción Socialista, sin ningún temor a la forma como reaccione la jauría antidemocrática, viene ahora a cumplir con su deber cívico abriéndole las puertas del sufragio a los ciudadanos a quienes sin ninguna razón legal, ni moral se las ha cerrado el Tribunal Supremo de Elecciones. Concretamente le ofrecemos al Bloque de Obreros, Campesinos e Intelectuales, campo en nuestras papeletas 
para sus candidatos y campo en nuestras tribunas para que expliquen al pueblo sus puntos de vista frente a los problemas nacionales” (46).

En ese nuevo escenario político, el señor Frank Marshall, la emprendió contra el Partido Acción Socialista, pretendiendo que la Asamblea Legislativa o el Tribunal Supremo de Elecciones, pongan fuera de ley a este Partido. De acuerdo a la postura del señor Marshall, Marcial Aguiluz afirmó: "Que él creyó en 1948 pelear por la libertad del sufragio , y nunca tomó las armas para enfrentarse al pueblo por sus conquistas sociales, alcanzadas bajo la orientación de Vanguardia Popular. Sigo peleando por lo mismo, por la libertad de sufragio, razón por la cual le he dado campo en las papeletas de mi Partido a los candidatos del Bloque, a fin de que millares de costarricenses tengan la oportunidad legal de votar por hombres capaces y honrados, con una larga vida de sacrificio al servicio del pueblo ... un contrabandista cuyo nombre no pronuncio para no mancharme la boca, pretende que la Asamblea Legislativa ilegalice al Partido Acción Socialista. Esa pretensión es vana, no tiene base legal, ni desde luego ninguna moral” (47).

En las nuevas condiciones histórico-concretas, el Partido Acción Socialista, celebró su Asamblea Nacional el 28 de setiembre de 1969, y acordó postular las candidaturas a la Presidencia y Vice-Presidencia; y además de los candidatos a diputados/as en las siete provincias del país.

La candidatura presidencial recayó en el médico, Tisiólogo, Sub-Director del Hospital Nacional Antituberculoso. Y en las vice-presidencias en el Prof. Víctor Manuel Arroyo, Catedrático de la Universidad de Costa Rica, escritor y hombre de combate en los combates populares, y en la Prof. Luisa González, la gran luchadora del pueblo, ejemplo de coraje, de vigor y de revolucionaria. De igual forma, las papeletas a Diputados/as fueron encabezadas por:

San José: $\quad$ Lic. Manuel Mora Valverde

Alajuela: Dr. Oscar Morera Madrigal

Cartago: Dr. Gilberto Bonilla Rojas

Heredia: Prof. Nidia Sáenz

Guanacaste: Prof. Adán Guevara Centeno 


\section{Puntarenas: $\quad$ Prof. Arnoldo Ferrero Segura}

Limón: $\quad$ Lic. Alvaro Montero Vega (48).

El 14 de octubre de 1969, Manuel Mora Valverde, pronunció por los canales de televisión 4 y 9 y Radio Tic-Tac, un discurso titulado “Abra los ojos el Pueblo”, en dicha alocución puede deducirse que en ella está plasmada la plataforma de lucha y trabajo del Partido Acción Socialista, él enfatizó en que "Iremos a las elecciones y luego a la Asamblea Legislativa y a las Municipalidades, a cumplir con nuestro deber de hombres honrados y de costarricenses. Lucharemos por un programa científico y realista, que significa un cambio profundo de la vida económica y social del país, el cual permitirá al pueblo costarricense vivir una verdadera democracia. Nos opondremos a cualquier entrega de las riquezas de nuestro país. Lucharemos para que se termine el festín escandaloso de las exenciones aduaneras. Lucharemos porque las compañías extranjeras paguen impuestos como los están pagando hasta los costarricenses más humildes. Combatiremos sin descanso todos los procedimientos empíricos que han conducido al desbarajuste de la hacienda pública. Nos opondremos a que los dineros públicos se gasten en edificios suntuosos y en carreteras de lujo, en vez de aplicarlos a construir caminos agrícolas y suministrar préstamos baratos a los agricultores y a los industriales nacionales. Defenderemos la soberanía nacional, siempre que la consideremos amenazada cualesquiera sean los sacrificios que debamos hacer para defenderla. Estas promesas tienen el respaldo de 40 años de lucha dura y real contra fuerzas muy grandes y oscuras. Esas fuerzas a las que nunca quisimos entregarnos, son las que ahora maniobran contra nosotros” (49).

Cuando se manifestó, que el apoyo a la participación de los comunistas en los procesos electorales, no era una actitud voluntarista, sino que ello obedecía a un estado de conciencia democrática de vastos sectores de la sociedad costarricense, que confiaban en las jornadas de lucha patriótica por espacio de 40 años, ello se manifiesta en las siguientes declaraciones de costarricenses de diversa filiación política e ideológica.

“Don Rafael Angel Arias Gómez, Presidente Municipal de San José, expresó: “Impedir la participación del Partido Acción Socialista, en las próximas elecciones es un hecho antidemocrático". 
Don Alberto Di Mare, Ministro de Planificación, adujo: "Si nuestro Poder Legislativo una vez más impide a un grupo de ciudadanos su derecho a la expresión habrá llegado el contrasentido de que, so pretexto, de impedir que lleguemos a convertirnos en Estado Totalitario, lo seamos efectivamente desde ahora”.

El diputado don Arnulfo Carmona, argumentó: "Definitivamente yo no estoy de acuerdo en que se proscriba a ningún partido político. Dentro del régimen democrático, todos absolutamente todos los ciudadanos tienen derecho a expresar sus ideas y manifestarse en las urnas electorales”.

El diputado Fernando Guzmán Mata, dijo: "Yo soy de los diputados con cuyo voto no se proscribirá al PASO, ni a ningún otro partido o agrupación política, que se constituya en el país”.

El Dr. Luis Barahona Jiménez, fundador del Partido Democráta Cristiano, fue enfático al apuntar: "Estamos ante un dilema que debemos resolver con valentía, o se reforma inmediatamente el artículo 98 de nuestra Constitución, o se reconocen los derechos de ciudadanos costarricenses a dar la batalla por sus convicciones políticos en el Partido Acción Socialista durante la presente campaña y en las elecciones de 1970" (50).

Ya en plena campaña electoral, los candidatos/as, se movilizaron por todo el país, llevando el mensaje del Partido Acción Socialista, en la Zona Sur, Arnoldo Ferreto: "Denunció enérgicamente las maniobras de la United Fruit Co., que primero se opone al ejercicio de la libre sindicalización, para luego imponer el llamado "arreglo directo"; y Marcial Aguiluz, en San José, señaló: "Estas no serán unas elecciones más en la Historia de Costa Rica. Por primera vez en veinte años, hombres verdaderamente preocupados por los problemas del pueblo, van en la papeleta de un partido que también es del pueblo, para luchar por una Costa Rica mejor”.

El Dr. Lisímaco Leiva, Candidato Presidencial, advirtió: "La miseria es el campo de cultivo, donde se desarrollan principalmente todas las enfermedades. Más de una tercera 
parte de la población total del país, no tiene suministro de agua normal, más de la mitad de los costarricenses no tienen servicio sanitario de ninguna clase, lo cual provoca una desmedida proliferación de parásitos intestinales de todo tipo, que en última instancia minan la vida de los costarricenses".

Dr. Gilberto Bonilla Rojas, Candidato a Diputado por Cartago, señaló: “No hay duda de que los grandes problemas de salud que afrontamos los costarricenses, nos obligan a pensar en la urgencia de reestructurar debidamente la organización del Seguro Social. Lo anterior no se debe tomar en demérito de Seguro Social. No. El Seguro Social es bueno, y lo considero una de las conquistas más importantes de los costarricenses”.

“Creo que como se mantiene en el Programa del Partido Acción Socialista, la desnutrición y otros males de nuestro pueblo se solucionarán cuando un gobierno-integrado por una coalición de fuerzas democráticos, antifeudales y antiimperialistas-emprender la reforma agraria y el rescate y la explotación en beneficio de nuestro pueblo de las riquezas que la naturaleza nos dio", de esta manera se manifestó el Dr. Oscar Morera, Candidato a Diputado por la provincia de Alajuela.

El Lic. Alvaro Montero Vega, argumentó: “Limón ha sufrido la explotación de muchas compañías extranjeras como la Northern Railway Co. y la United Fruit Co. Compañías extranjeras y latifundistas, muy conocidas se han apoderado de miles y miles de hectáreas de tierras de Sixaola hasta Tortuguero. Además, lucharé porque el derecho a la cesantía se reforme para que el trabajador no lo pierda nunca por ningún motivo, convirtiéndolo en un derecho adquirido" (51).

Los resultados electorales, de acuerdo a la votación del mes de febrero de 1970, arrojó para el Partido Acción Socialista los datos que siguen:
Para Presidente:
7.221
Para Diputados:
29.133
Para Regidores: 
Esto a nivel nacional, lo que implica porcentualmente que:

La votación presidencial fue de 1.36\%

Votación para Diputados fue de 5.49\%

Votación para Regidores fue de 3.77\%

Lo anterior de un Padrón Electoral donde estaban inscritos 675.285 votantes. Ejercieron el voto 530.425 lo que significó un 83.34\% y un Abstencionismo del 16.7\%.

La votación para Diputados del Partido Acción Socialista

\begin{tabular}{|l|r|r|r|}
\hline \multicolumn{1}{|c|}{ Provincia } & $\begin{array}{r}\text { Votación } \\
\text { Obtenida }\end{array}$ & Cociente & Subcociente \\
\hline San José & 17.119 & 10.350 & 5.175 \\
\hline Alajuela & 2.300 & 9.550 & 4.715 \\
\hline Cartago & 1.779 & 8.602 & 4.301 \\
\hline Heredia & 2.093 & 12.872 & 6.436 \\
\hline Guanacaste & 717 & 8.161 & 4.081 \\
\hline Puntarenas & 3.066 & 6.993 & 3.497 \\
\hline Limón & 2.069 & 6.942 & 3.471 \\
\hline
\end{tabular}

Lo anterior implicó, que el Partido Acción Socialista logró elegir dos diputados a la Asamblea Legislativa, ellos fueron Manuel Mora Valverde (Secretario General del Partido Vanguardia Popular) y Marcial Aguiluz Orellana, ambos por la provincia de San José.

Anivel nacional el Partido Acción Socialista eligió 4 Regidores Propietarios y 5 Suplentes, distribuidos geográficamente como sigue:

San José

Golfito

Osa

Limón Centro
1 Regidor Propietario

1 Regidor Propietario

1 Regidor Propietario

1 Regidor Propietario
2 Regidores Suplentes

1 Regidor Suplente

1 Regidor Suplente

1 Regidor Suplente 
En el resultado global, el Partido Acción Socialista se constituyó en la tercera fuerza política-electoral, por debajo de los Partidos Liberación Nacional y Unificación Nacional.

\section{CONCLUSIONES}

Con base en lo expuesto anteriormente, se puede llegar a diversas conclusiones de lo que significó para el Partido Vanguardia Popular, la Campaña Electoral de 1970.

Esta jornada, significó un proceso más de enseñanzas políticas, por cuanto si bien se hizo énfasis de modo reiterado, que los comunistas de Costa Rica optaban por la vía pacífica para desarrollar el proceso revolucionario en nuestro país, esa tesis poco o nada, le importó a los sectores de la clase económicamente dominante. Pues esta no tuvo ningún reparo, en continuar con su línea antidemocrática como lo había hecho desde que concluyó la guerra civil de 1948.

Importante advertir, que la clase política y económicamente dominante, sí tenía los objetivos muy claros de que se trataba de confrontar al principal enemigo de clase, vale decir, al destacamiento revolucionario de la clase obrera y demás sectores subalternos, al Partido Comunista, al que había que mantener en el ostracismo al precio que fuera. Y para ello, tenían todo el aparato del Estado para lograrlo, más el apoyo incondicional del imperialismo estadounidense.

De modo que, esta experiencia, como toda lucha política y social dejó enseñanzas de gran valía.

Quedó claro la necesidad de consolidar más al Partido, desde el punto de vista orgánico e ideológico, para de esta forma, lograr insertarse y ganar la conciencia de los sectores populares.

La experiencia histórica demostró, de manera muy palmaria que en la lucha de clases, la organización revolucionaria, debe ser firme en sus principios doctrinarios, pero eso sí, teniendo la capacidad táctica de flexibilizar cuando las condiciones políticas objetivas y subjetivas así lo permitan. 
El Partido Vanguardia Popular no se amilanó ni por asomo, cuando el Tribunal Supremo de Elecciones proscribió al Bloque de Obreros, Campesinos e Intelectuales. De inmediato forjó una acción unitaria con el Partido Acción Socialista, encabezado por un auténtico socialdemócrata. Esa alianza demostró precisamente la flexibilidad táctica ha que hacíamos referencia líneas atrás, la alianza de por sí, no es abandonar los principios, todo lo contrario, más bien las puede consolidar siempre y cuando, estén bien definidos los lineamientos de la misma, porque no se trata de aliarse por aliarse, y sacar más votos y elegir más diputados o regidores, no, se trata de trabajar unitariamente con entereza, responsabilidad, lealtad y firmeza para que los postulados teóricos y las propuestas reivindicativas logren ser asimiladas por la sociedad civil y buscar canales para esa sociedad civil se integre a las tareas para construir una sociedad justa y equitativa.

Importante fue el hecho de que el Partido Acción Socialista, se constituyera en la tercera fuerza política del país, eso la estimuló como tal, pero también la obligó a replantearse como mejorar sus métodos de trabajo, como de modo autocrítico asumir una postura sí de principios, pero no hegemonista en el seno del movimiento obrero y popular.

La campaña electoral demostró de modo fehaciente, una conducta de extremo sometimiento a la política exterior de la Unión Soviética, - nadie ni por asomo está insinuando una actitud antisoviética - lo que sí es cierto, es que hubo poco análisis para enfrentar las problemáticas surgidas en el seno mismo del movimiento comunista internacional, particular el problema Chino-Soviético y el conflicto interno de Checoesvolaquia con la posterior intervención del Pacto de Varsovia.

De igual forma se requería un análisis más sereno, más político, para tratar el asunto tan crucial de las vías de la revolución, flaco favor se hace al movimiento revolucionario nacional e internacional cuando no se debaten tesis por el fondo, sino que el Partido Vanguardia Popular se queda en la superficie, la cual le permite caer fácilmente en postularon dogmática y sectarias, calificando con adjetivos que no corresponden, como por ejemplo decir que las organizaciones revolucionarias que optan por la vía armada son ultraizquierdistas, aventuras, pequeño burguesas radicalizadas, eso no dice nada, absolutamente nada, como marxistas leninistas se tiene que auscultar a profundidad, discutir con planteamientos que sean interpretaciones no sacadas de las 
gavetas de un escritorio, sino de la realidad, de la cotidianidad, de lo que piensan y reflexionan los diversos actores sociales en un momento histórico determinado, ya lo apuntaba Lenin: "audacia, audacia y más audacia” y agregaba: "las cosas hay que analizarlas como son, no como se supone que son”.

Otra enseñanza histórica de esta jornada de lucha, que constituyó la Campaña Electoral de 1970 fue la necesidad de asimilar que si bien es cierto el marxismo-leninismo no es un dogma, sino una guía para la acción, el marxismo-leninismo no es solo los clásicos de Marx, Engels y Lenin, por lo demás harto valiosos y aleccionadores, pero el marxismo precisamente ha logrado como método de análisis interpretaciones en extremo aleccionadoras, tales como las de Rosa Luxemburgo, Antonio Gramsci, Palmiro Togliatti, Perry Anderson, José Carlos Mariátegui, Nicos Poulantzas, Louis Althusser, Roger Garudy, Ernesto Che Guevara, Carlos Rafael Rodríguez, León Trostky, y hay la necesidad de leerlos y releerlos y sacar las cuestiones o aportes que se consideren válidos para el proceso de construcción de una sociedad socialista.

Una conclusión nada despreciable, todo lo contrario, un aporte al movimiento revolucionario es que los comunistas costarricenses ganaron su derecho a participar en las elecciones desplegando una política de principios y una flexibilidad táctica, lo cual permitió ganarle la partida política a la burguesía entreguista y al imperialismo, me refiero haber participado llevando el mensaje al pueblo siendo un partido ilegal, e ilegal eligió Diputados y Regidores, esto no es un hecho cualquiera, esto es una enseñanza y debe ser asimilada como tal. 


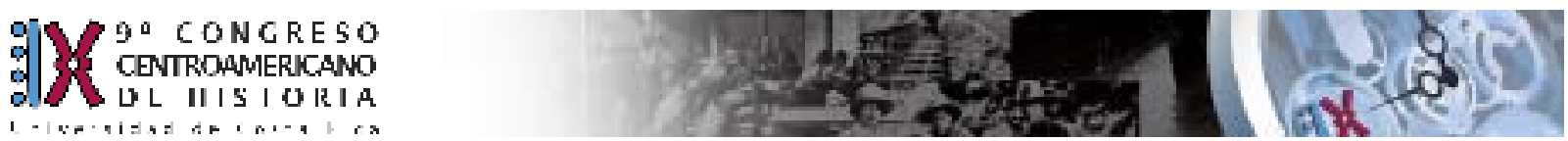

Indexaciones: Repositorio de Revistas UCR, DIALNET, Latindex, REDALYC Directorio y recolector de recursos digitales del Ministerio de Cultura de España, Directory of Open Access Journals. Diálogos Revista Electrónica de Historia ISSN 1409-469X. Número especial 2008. Dirección web: http://historia.fcs.ucr.ac.cr/dialogos.htm

\section{CITAS Y NOTAS}

1- $\quad$ Véanse las obras La Ideología Alemana, en esta Marx y Engels, abandonaron su antigua concepción humanista, introducen los nuevos conceptos de la teoría del materialismo histórico, critican la concepción idealista de Hegel y la concepción materialista contemplativa de Feuerbach. (Marx-Engels. La Ideología Alemana, Ediciones Pueblos Unidos, Montevideo, Uruguay, 1958); y en el Manifiesto Comunista, particularmente Engels advierte en el prefacio a la edición alemana de 1883, que "La idea fundamental de que está penetrado todo el Manifiesto, a saber, que la producción económica y la estructura social que de ella se deriva necesariamente en cada época histórica constituyen la base sobre la cual descansa la historia política e intelectual de esa época” (Marx-Engels: El Manifiesto Comunista, en Obras Escogidas, Editorial Progreso, Moscú, Unión Soviética, 1972, págs. 12-49).

2- $\quad$ Estúdiese el análisis que hace Gramsci, en su artículo "La poda de la historia”, publicado en la edición de L’Ordine Nuovo del 7 de enero de 1919.

3- $\quad$ Véase conferencia dictada por el Dr. Víctor Hugo Acuña Ortega, en la ceremonia de apertura de la Carrera de Historia, en la Universidad de El Salvador, San Salvador, enero 2002, aparecida la Serie Cuadernos de Historia de la Cultura, \# 22, Sección Historia de la Cultura, Escuela de Estudios Generales, Universidad de Costa Rica, 2007, página 5.

4- $\quad$ Véase entrevista a don José Figueres Ferrer, realizada el 19 de abril de 1983, pág. 2, realizada por el autor de esta ponencia. Esta entrevista, se encuentra íntegra como anexo, en el artículo publicado en la Revista Diálogos, revista digital de la Escuela de Historia y del Centro de Investigaciones Históricas de América Central, dicho artículo se titula "Una lectura crítica de don José Figueres Ferrer en torno a la Guerra Civil de 1948 y su papel en la Junta Fundadora de la Segunda República”. El número de la revista es el No. 9, correspondiente a Febrero-Agosto del 2008.

5- $\quad$ Véase el texto titulado Los Años Cuarenta (Historia de una política de alianzas) de los autores Gerardo Contreras y José Manuel Cerdas, Editorial Porvenir, San José, Costa Rica, 1988, págs. 168-169.

6- $\quad$ Dicha moción se encuentra en el Acta No. 81, de la Asamblea Nacional Constituyente, del día dos de junio de mil novecientos cuarenta y nueve, Tomo II, Imprenta Nacional, San José, Costa Rica, 1955, página 232.

7- $\quad$ Véase las páginas 233, 236, 239, 300, los cuales corresponden a las Actas 81, 83, 85 de la Asamblea Nacional Constituyente.

8- $\quad$ Las opiniones de los diputados constituyentes, Luis Dobles Segreda, José Joaquín Jiménez Núñez y don Luis Felipe González Flores, se encuentran en las páginas 293, 295, 297, del Acta 85, del ocho de junio de mil novecientos cuarenta y nueve. Fue en esa misma sesión, que se votó la propuesta del diputado Volio Sancho, siendo el resultado de la votación 27 votos afirmativos y 17 negativos. Asamblea Nacional Constituyente de 1949, Actas, Tomo II, Imprenta Nacional, San José, Costa Rica, 1955.

9- Véase el texto Carlos Luis Sáenz: El escritor, el educador y el revolucionario, del autor Francisco Zúñiga Díaz, Ediciones Zúñiga y Cabal, San José, Costa Rica, 1991, páginas 352-353. 
10- $\quad$ Véase Periódico Adelante, página 11, domingo 1 de julio de 1962.

11- $\quad$ Véase Periódico La Nación del día 9 de marzo de 1948, página 4.

12- Consúltese la Colección de Leyes y Decretos. Decreto No. 306, Segundo Semestre 1948, páginas 437-

438.

13- $\quad$ Véase Periódico La Nación, del día 12 de diciembre de 1950, página 14.

14- $\quad$ Véase Periódico Adelante, del 18 de julio de 1954, páginas 1 y 6.

15- Véase el texto La Historia No es Color de Rosa, de Gerardo Contreras, a propósito del setenta y cinco aniversario de la fundación del Partido Comunista de Costa Rica, Editorial Perro Azul, San José, Costa Rica, 2006, páginas 104-105.

16- Véase el texto Reforma o Revolución, de Rosa Luxemburgo, Editorial Fontamara, Barcelona, España, 1978, páginas 33 y 34.

17- $\quad$ Para una mayor comprensión de lo acaecido en el proceso de reconstrucción del Partido Vanguardia Popular, es necesario estudiar de modo pormenorizado el documento Informe del Comité Central al IX Congreso del Partido, 14-15 y 16 de Abril de 1962.

18- $\quad$ Ibidem, pág. 52.

19- Véase el testo Clase Trabajadora y Organización Sindical en Costa Rica. 1943-1971 de la autora Marielos Aguilar, Editorial Porvenir - FLACSO, San José, Costa Rica, 1989, página 161.

20- Véase el texto de Vladimir Lenin, “El Trabajo del Partido entre las masas”, Editorial Progreso, Moscú, Unión Soviética, 1978, páginas 56-57.

21- Véase documento de Informe del Comité Central al IX Congreso del Partido, 14-15 y 16 de abril de 1962, páginas 64 y 65.

22- Véase el texto Historia de América Latina, cuyo tomo No. 14 se titula América Central desde 1930, Cambridge University, Compilador Leslie Bethell, Editorial Crítica, Barcelona, España, 2001, páginas 67 y 68.

23- Véase el Documento Informe Secreto al XX Congreso del PCUS, presentado por Nikita Khrushchev, en Moscú el 25 de febrero de 1956, Fuente de versión Digital. Marxismo.org., Ajuste del HTML para el MIA; Juan Fajardo, julio 2006, páginas 1-7-8-39.

24- Véase el texto Ensayos sobre América Latina, del autor Regis Debray, Ediciones ERA, México, D. F., México, 1971, páginas 125-126.

25- Véase Pasajes de la lucha revolucionaria, de Ernesto “Che” Guevara, Editorial de Ciencias Sociales, La Habana, Cuba, 1985, páginas 15-21-23-26-28. 
26- Véase La Guerra Revolucionaria de Carlos Marighella, Editorial Diógenes S. A., México D. F., México, 1971, páginas 11 y 18.

27- Véase Programa del partido Comunista de Chile, aprobado en marzo de 1962 por el XII Congreso. En: Ensayos sobre América Latina, de Regis Debray, Ediciones ERA, México, D. F., México, 1971, página 141.

28- Véase el texto Discursos de Manuel Mora Valverde 1934-1979, discurso pronunciado el 25 de enero de 1966, y el otro discurso cuya disertación fue hecha el 26 de agosto de 1968; Editorial Presbere, San José, Costa Rica, Primera Edición 1980, páginas 573 y 613.

29- Véase el texto La Otra Vanguardia, memorias Jaime Cerdas Mora, Editorial UNED, San José, Costa Rica, 1993, páginas 188-190-191-194-196.

30- Véase el texto Escritos Políticos, particularmente el apartado titulado Memorandum sobre las cuestiones del Movimiento Obrero Internacional y sobre su Unidad, escrito en 1964, Ediciones Era, México D. F., México, 1971, página 437.

31- Véase el texto La Revolución Vietnamita, del dirigente Le Duan, Editorial de Ciencias Sociales, La Habana, Cuba, 1971, páginas 21-28-29-214.

32- Véase el texto Discursos de Manuel Mora Valverde 1934-1979, discurso pronunciado el 26 de agosto de 1968. Editorial Presbere, San José, Costa Rica, Primera Edición 1980, páginas 618 y 619.

33- Véase el texto Por el Camino de Lenin, Discurso Cincuenta Años de Grandes Victorias del Socialismo, pronunciado por Leonid Brezhnev, Secretario General del Partido Comunista de la Unión Soviética. Editorial Progreso, Moscú, Unión Soviética, 1967, página 67.

34- Véase el texto Discursos de Manuel Mora Valverde 1934-1979, la disertación se tituló No Somos Cobardes Ni Oportunistas, pronunciado en el año 1969, Editorial Presbere, San José; Costa Rica, pág. 611.

35- $\quad$ Véase Periódico Libertad del 4 de enero de 1969, \# 312, página 1.

36- $\quad$ Ibidem, pág. 2.

37- Véase el documento de Informe del Comité Central al IX Congreso del Partido Vanguardia Popular, en el apartado No. XI titulado "El cambio de gobierno y la perspectiva política”, 14-15 y 16 de abril de 1962, página 79.

38- Véase Periódico Libertad, del 18 de Enero de 1969, página 4.

39- Véase Periódico Libertad, del 15 de febrero de 1969, \# 318, página 1.

40- $\quad$ Véase Periódico Libertad, Carta de Manuel Mora para don José Figueres Ferrer, edición del 15 de marzo de 1969, \# 322, página cinco.

41- Véase Periódico Libertad, Carta de Manuel Mora para don Rafael Angel Calderón Guardia, edición del 22 de marzo de 1969, \# 323, página 5. 
42- $\quad$ Véase Seminario Libertad, del 12 de abril de 1969, edición \# 325, página 6.

43- $\quad$ Véase Semanario Libertad, del 31 de mayo 1969, Edición \# 332, página 5.

44- $\quad$ Véase Semanario Libertad, del 12 de julio 1969, Edición \# 338, página 4.

45- Véase el texto Discursos de Manuel Mora Valverde 1934-1979. La exposición se titula "No Somos Cobardes Ni Oportunistas”, Editorial Presbere, San José, Costa Rica, páginas 611 y 612.

46- $\quad$ Véase Semanario Libertad, \# 343, 16 de agosto de 1969, página 4.

47- $\quad$ Véase Semanario Libertad, \# 348, 20 de setiembre de 1969, página 5.

48- $\quad$ Véase Semanario Libertad, \# 351, del 11 de octubre de 1969, página 7.

49- $\quad$ Véase Semanario Libertad \# 352, del 18 de octubre de 1969, página 5.

50- $\quad$ Véase Semanario Libertad \# 354, del 1 de noviembre de 1969, página 4.

51- $\quad$ Véase Semanario Libertad \# 362, del 10 de enero de 1970, página 6.

52- Véase Memoria del Tribunal Supremo de Elecciones, Votaciones para Presidentes, Vicepresidentes, Diputados, Regidores y Síndicos, Febrero 1970. Imprenta y Litografía Lil S. A., San José, Costa Rica, 1970. 


\section{BIBLIOGRAFÍA}

Acuña O., Víctor. Historia e Incertidumbre. Serie Cuadernos de Historia de la Cultura \# 22. Editorial Universidad de Costa Rica, San José, Costa Rica, 2007,

Aguilar H., Marielos. Clase Trabajadora y Organización Sindical en Costa Rica 1943-1971. Editorial Porvenir - FLACSO, San José, Costa Rica, 1989.

Aguiluz C., Evangelina. Compañero Marcial Aguiluz ¡Presente! Su lucha en América Central. Editorial Tecnológica de Costa Rica, Cartago, Costa Rica, 2003.

Araya, Victorio et al. Teología de la Liberación. Departamento Ecuménico de Investigaciones, San José, Costa Rica, 1984.

Alvarenga V., Ana Patricia. Los Ciudadanos y el Estado de Bienestar. Serie Cuadernos de Historia de las Instituciones de Costa Rica \# 14. Editorial Universidad de Costa Rica, San José, Costa Rica, 2005.

Bethel, Leslie. Historia de América Latina. 14. América Central desde 1930, Cambridge University Pres, Editorial Crítica, Barcelona, España, 2001.

Bogush, Eugeni. El maoismo y la política de división en el Movimiento de Liberación Nacional. Editorial Progreso, Moscú, Unión Soviética, s.f.e. 
Brezhnev, Leonid. Por el Camino de Lenin. Editorial Progreso, Moscú, Unión Soviética, 1972.

Carr, E.H. ¿¿Qué es la Historia? Editorial Seix Barral S. A., Barcelona, España, 1978.

Cerdas C., Rodolfo. La Hoz y el Machete. Editorial UNED, San José, Costa Rica, 1986.

Cerdas M., Jaime. La Otra Vanguardia. Editorial UNED, San José, Costa Rica, 1993.

Cerroni, Umberto et al. Teoría Marxista del Partido Político. Ediciones Pasado y Presente, México D. S:, México, 1987.

Chinchilla, José Carlos et al. El sistema de partidos políticos en Costa Rica durante la segunda mitad del siglo XX. Serie Cuadernos de Historia de las Instituciones de Costa Rica, Editorial Universidad de Costa Rica, 2005.

Contreras, Gerardo. La Historia No es Color de Rosa. Ediciones Perro Azul, San José, Costa Rica, 2006.

González G., Luisa. Escritos. Editorial Universidad Nacional, Heredia, Costa Rica, 2006.

Gramsci, Antonio. La poda de la historia. L'Ordine Nuovo, 7 de enero 1919. Marxists Internet Archive, 2001. 
Corralán, Luis. Tres períodos en nuestra línea revolucionaria. Grafischer Dresden, República Democrática Alemana, 1982.

Debray, Régis. Ensayos sobre América Latina. Ediciones ERA, México D. F., México, 1971. . La Guerrilla del Che. Editorial Siglo XXI, México D. F., México, 1985.

Díaz A., David et al. Tiempos de reflexión: la primera polémica historiográfica costarricense. Editorial Universidad de Costa Rica, San Juan, Costa Rica, 2007.

Herrera G., Adolfo et al. Partido Vanguardia Popular. Breve esbozo de su Historia. Ediciones Revolución, San José, Costa Rica, 1971.

Guevara, Ernesto. Punta del Este (Proyecto Alternativo de desarrollo para América Latina). Centro de Estudios CHE GUEVARA, La Habana, Cuba, 2006.

Guililov, S. et al. Problemas del Movimiento Comunista. Editorial Progreso, Moscú, Unión Soviética, 1975.

Lassalle, Fernando. ¿Qué es una Constitución? Ediciones Siglo Veinte, Buenos Aires, Argentina, 1964. 
Lenin, Vladimir. El trabajo del Partido entre las masas. Editorial Progreso, Moscú, Unión Soviética, 1978.

Le Duan. La revolución vietnamita. Editorial de Ciencias Sociales, La Habana, Cuba, 1971.

Luxemburg, Rosa. Reforma o Revolución. Editorial Fontamara, Barcelona, España, 1978.

Malavassi, Ana Paulina. Historia ¿ciencia, disciplina social o práctica literaria?, Editorial Universidad de Costa Rica, San José, Costa Rica, 2006.

Marighella, Carlos. La Guerra Revolucionaria. Ediciones Diógenes S. A., México D. F., México, 1971.

Marx-Engels. La Ideología Alemana. Ediciones Pueblos Unidos, Montevideo, Uruguay, 1958.

Marx-Engels. Manifiesto Comunista, en Obras Escogidas, Editorial Progreso, Moscú, Unión Soviética, 1972.

Mao Tse Tung. La revolución china. Akal Editor, Madrid, España, 1976.

Mora V., Eduardo. 70 años de militancia comunista. Editorial Juricentro, San José, Costa Rica, 2000. 
Mora V., Manuel. Discursos 1934-1979. Editorial Presbere, San José, Costa Rica, 1980.

Morales, Juan Rafael. Escribo para recordar. Editorial UNED, San José, Costa Rica, 2000.

Obregón Q., Clotilde. El proceso electoral y el Poder Ejecutivo en Costa Rica. Editorial Universidad de Costa Rica - Tribunal Supremo de Elecciones, San José, Costa Rica, 2000.

Olivares O., Javier. Camarada Pingüino. URUK Editores, San José, Costa Rica, 2006.

Reiman, Michal. El nacimiento del estalinismo. Editorial Crítica, Editorial Crítica, Barcelona, España, 1982.

Rodríguez, Carlos Rafael. Letra con Filo Tomo II. Editorial de Ciencias Sociales, La Habana, Cuba, 1983.

Togliatti, Palmiro. Escritos Políticos. Ediciones ERA, México, D. F., México, 1971.

Zúñiga, Francisco. Carlos Luis Sáenz. Ediciones Zúñiga y Cabal, San José, Costa Rica, 1991.

\section{DOCUMENTOS}

Actas Asamblea Nacional Constituyente, Tomos II y III, Imprenta Nacional, San José, Costa Rica, 1955.

Informe del Comité Central al IX Congreso del Partido Vanguardia Popular, 14-15 y 16 Abril de 1962, San José, Costa Rica, s.f.e. 
Informe Secreto al XX Congreso del Partido Comunista de la Unión Soviética, presentado por Nikita Khrushchev, el 25 de febrero de 1956, fuente de la versión digital: Marxismo. org.

Memoria del Tribunal Supremo de Elecciones, Votaciones para Presidente, Vicepresidente, Diputados, Regidores y Síndicos, Febrero 1970. Imprenta y Litografía Lil S. A., San José, Costa Rica, 1970.

\section{PERIÓDICOS Y REVISTAS}

Colección Semanario Libertad de los años 1969 y 1970, propiedad del Partido Vanguardia Popular, Marzo, Abril, Mayo 2008, San José, Costa Rica.

Colección de Revistas TRABAJO, Órgano del Comité Central del Partido Vanguardia Popular, Tercera Época, 1970 y 1971, San José, Costa Rica. 